\title{
In situ control of graphene oxide dispersions with a small impedance
}

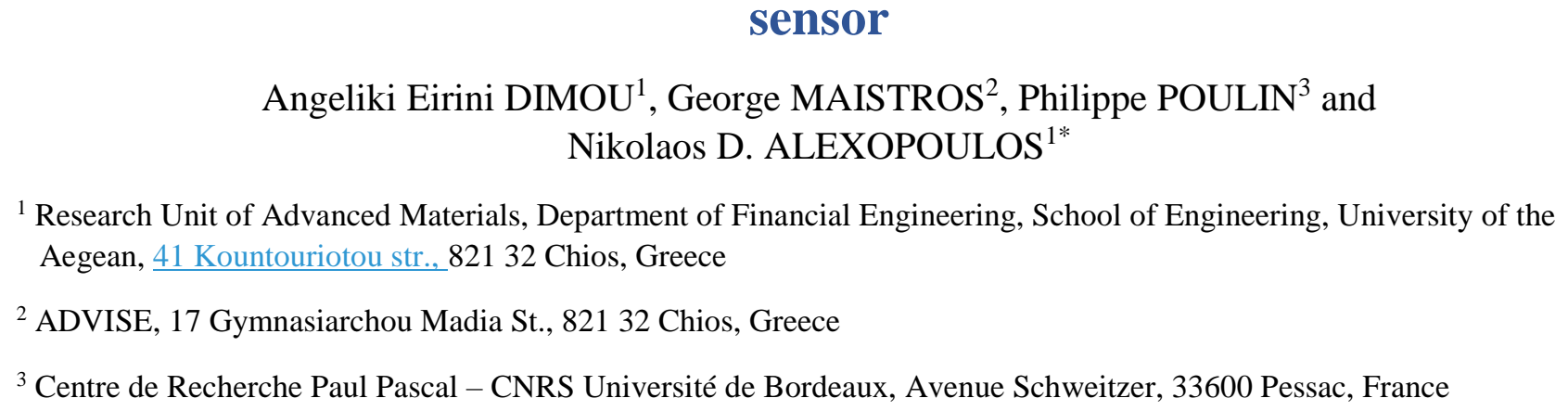

Carbon-based nanomaterials (CBNs), such as graphene and carbon nanotubes, display advanced physical and chemical properties, which has led to their widespread applications. One of these applications includes the incorporation of CBNs into cementitious materials in the form of aqueous dispersions. The main issue that arises in this context is that currently no established protocol exists as far as characterizing the dispersions. In the present article, an innovative method for quick evaluation and quantification of Graphene Oxide (GO) dispersions is proposed. The proposed method is Electrical Impedance Spectroscopy (EIS) with an impedance sensor. The novelty lies on the exploitation of a small sensor for on-site (field) direct dielectric measurements with the application of alternating current. Five different concentrations of GO dispersions were studied by applying EIS and for various accumulated ultrasonication energies. The low GO concentration leads to high impedance values due to low formed current network. The ultrasonication revealed two opposing mechanisms that are happening simultaneously: it facilitates the flow of the electric current due to the formation of a better dispersed network (break of the agglomerates), nevertheless the surface hydrophilic structure of the GO is damaged with the high accumulated ultrasonication energy. The dielectric measurements were exploited to express an appropriate quantitative "quality index" to facilitate with the dispersion control of the nanostructures. An intermediate concentration of GO is suggested (about $0.15 \mathrm{wt} \%$ of the binder materials) to be optimal for the specific engineering application, ultrasonicated at approximately 30 to $65 \mathrm{~kJ}$. The investigated methodology is highly novel and displays a high potential to be applied in-field applications where CBNs must be incorporated in building materials.

Keywords: Electrical Impedance Spectroscopy (EIS); Graphene Oxide (GO); Dispersions; Ultrasonication Energy;

\footnotetext{
*Corresponding author: Tel: +30 2271035464. E-mail: nalexop@ aegean.gr 


\section{Introduction}

Nanomaterials possess original properties and novel characteristics in comparison to their equivalent bulk materials [1]. One category of nanomaterials is carbon-based nanomaterials (CBNs) and includes among other carbon nanotubes (CNTs), nanodiamonds and Graphene (G). Those materials combine extraordinary physical and chemical properties, e.g. electrical conductivity and high mechanical strength [2].

Graphene Oxide (GO) is a derivative of Graphene and contains different oxygen functional groups. These oxygenated groups are the reason for $\mathrm{G}$ and $\mathrm{GO}$ to have some differences in their mechanical and electrochemical properties, e.g. [3]. G and GO have been used so far in many different applications [4], such as lithium-ion batteries, supercapacitors, biosensors ${ }_{2}$ etc. One of the most challenging application of $\mathrm{G}$ and its derivatives is their incorporation in construction materials such as cement and concrete. The majority of investigations on this research topic demonstrated that these materials when added in small weight percentages (wt\%) in the respective matrices, increase substantially the mechanical, electrical and piezoresistive properties, e.g. by Metaxa [5] and Guo et al. [6].

Possibly the best strategy to incorporate the CBNs in the cement matrix is the prior (appropriate) dispersion of the nanomaterials in the mixing water with cement. This task has been challenging to overcome so far, not only in the case of cement-based composites but also in all CBN applications, since the nanoparticles tend to agglomerate in solutions. This phenomenon leads to the reduction of the specific surface area of the nanoparticles [7], as well as to an inhomogeneous dispersion of the nanoparticles in the cement matrix. Zhao et al. [8] reported that the lack of homogeneity results in the creation of weak zones in the final product. To this end, it is extremely important to break down any-formed agglomerates and to efficiently disperse the nanoparticles in order to form so that a stable system is formed. To achieve this goal, different dispersion systems and methods have been investigated in the literature for the CBN dispersion and representative research articles are reported in Table 1Table 1.

The literature review revealed that the application of ultrasonic energy, is possibly the best means to achieve 'good'CBN dispersions. Several differences were noticed regarding the type of additional agents employed (surfactants, superplasticizers, etc.) to increase the dispersion "quality". There are also several attempts to chemically functionalize the nanomaterials before their dispersion phase. For example, Wang et al. [9] functionalized GO with polyether amine, while Sezer and Koç [10] acid-functionalized CNTs and silver-decorated CNTs to enhance their capability to be efficiently dispersed. 
122 Apart from forming dispersions with the necessary CBN type and concentration, another important issue 123 is their characterization in terms of dispersion degree. The zeta potential $(\zeta)$ through Dynamic Light 124 Scattering (DLS) is a widely used method, e.g. in [8], [10]_-and [11], to characterize an aqueous dispersion. Another method that is frequently exploited to characterize the stability of such dispersions is Ultraviolet-Visible (UV-Vis) Spectroscopy, e.g. [12] and [13]. Vallejo et al. [14] calculated several rheometric parameters, while Konios et al. [15] determined their solubility factors. A literature review with the available methods to characterize the dispersion of nanomaterials in solutions can be found in Table 1Table 1 . All these methods can be performed on the same system to get an advanced-insight of the dispersion with the combination of all available (conventional and less-conventional) methods for the advanced characterization control. Nevertheless, most of these methods suffer fremare subjected to limitations, like including the need to dilute the suspensions, the use of specific cells with well-defined optical characteristics, the need of large analysis instruments, etc. All these factors are limiting the This

widespread and easily implementationis why they cannot be easily implemented for the in-situ characterization of suspensions in various environments and applications.

The present article aims at introducing a light and versatile methodology for the nanomaterials dispersion control with a small sensor by exploiting Electrochemical Impedance Spectroscopy (EIS). By measuring the dielectric properties, process-related conclusions can be madeinvestigated. Dielectric Analysis, also known as impedance spectroscopy, is an already mature technology for the measurement of the dielectric properties, the investigation of the mechanisms and the kinetics of reactions, as well as of properties of porous materials, e.g. by Macdonald [16].

As far as the characterization of the dispersions of nanomaterials is concerned, Impedance SpectroscopyEIS has also been applied successfully. For instance, Alfonso et al. [17] examined GO solutions in Milli-Q water and Isopropyl Alcohol to find relatively small values of dielectric permittivity in graphene oxide materials in comparison to previous studies. Baltzis et al. [18] applied impedance spectroscopyEIS to study epoxy composites with CNTs and milled carbon and found out that the results indicated an inverse dependence between the magnitude of impedance and the dispersion duration. The reason for this increasing interest on the characterization of systems with this method is the simplicity of the method and the relatively low cost of the measuring technology.

150 In the present study, a novelty is introduced for the proposed methodology that exploits a small (field) sensor for in-situ direct dielectric measurements with the application of alternating current. It is noted that the classic EIS setup with the parallel electrodes makes the exploitation of the methodology difficult 
153 in on-field applications. Also, EIS has already been applied to study the behaviour of cementitious materials, as described in [19] and [20], but this would not be feasible in field.

155 The present article focuses on the first step of the production of GO/cement composites, i.e. the 156 development of the aqueous nanoparticle dispersion before being added in the cementitious matrix. The 157 final research target is to produce a composite with electrical and piezoresistive properties, thus 158 permeating the sensing ability. To this end, it will be shown that the proposed method can be used for a 159 quick, efficient, and quantitative evaluation of the CBN dispersions in applications. To achieve this 160 target, five different GO dispersions with varying GO concentration will be produced. Ultrasonication 161 energy with a probe ultrasonicator is applied on all aqueous dispersions and their electrical properties are 162 measured through the application of EIS. The results of the methodology are analysed to characterize the 163 dispersion control and several other analytical techniques like Fourier-Transform Infrared Spectroscopy 164 (FT-IR), Raman Spectroscopy and Optical Microscopy were also used to support the findings of the 165 present investigation.

\section{Experimental investigation}

167 The experimental flow diagram can be shortly summarised as follows: firstly, the water and graphene 168 oxide are mixed to form the GO dispersion. Then, ultrasonication energy is applied to the aqueous 169 dispersion, while impedance scans are recorded at different accumulated ultrasonication energy values. 170 Samples at the same ultrasonication values are isolated to be examined with analytical methods, e.g. 171 optical microscopy, FT-IR and RAMAN spectroscopy. The results are assessed to fully analyse the 172 aqueous dispersions so that an optimal concentration and amount of ultrasonication energy can be 173 proposed. A schematic representation of the flow diagram of the present article is given in Figure 1. 


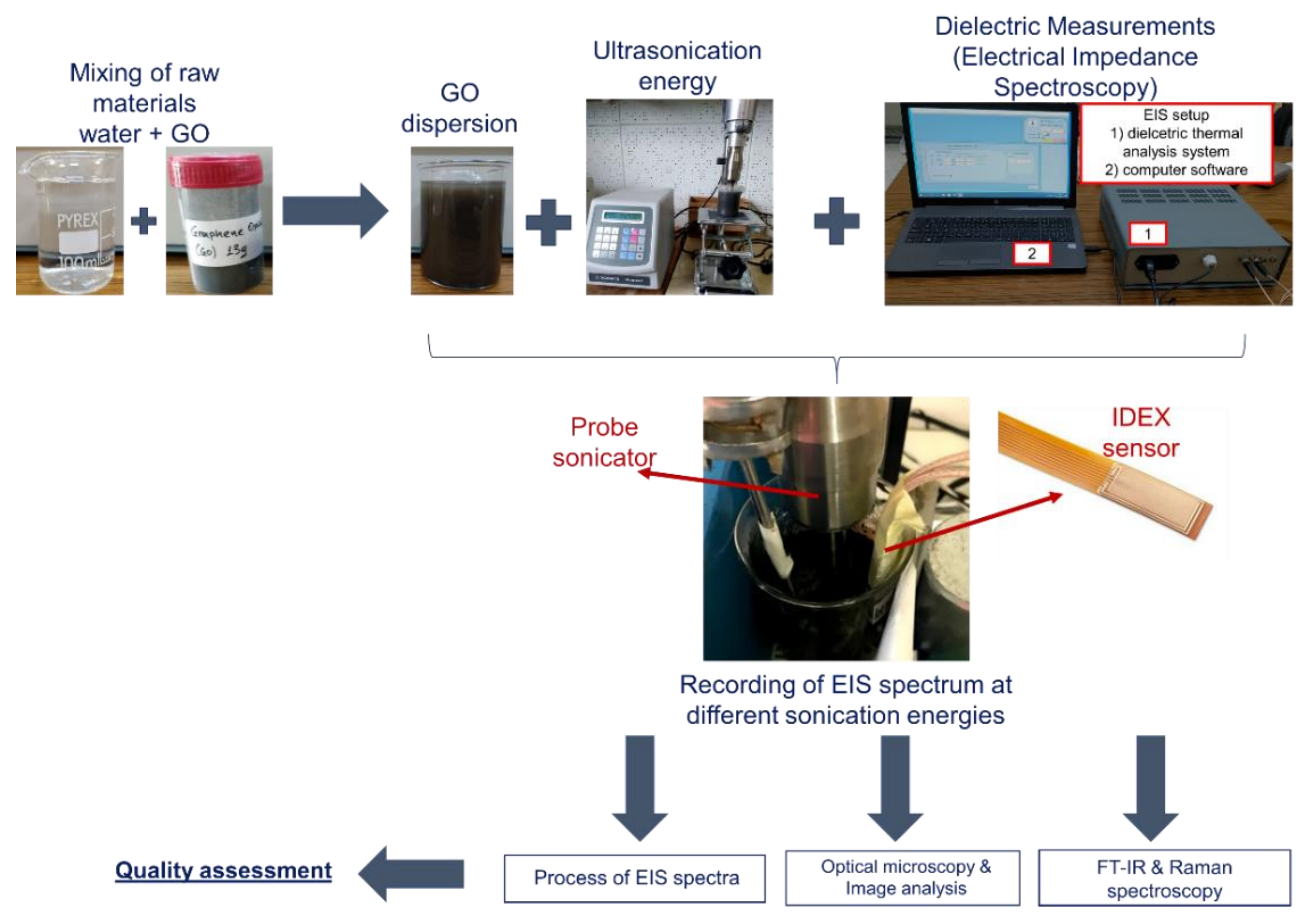

Figure 1. Schematic representation of the experimental procedure.

177 Table 1: List of dispersion evaluation methods for different dispersion systems of CBNs.

\begin{tabular}{|c|c|c|c|c|c|}
\hline Ref. & Nanomaterial & Dispersion system & $\begin{array}{l}\text { Concentration / } \\
\text { Content }\end{array}$ & Dispersion method & Evaluation method \\
\hline [12] & G & $\begin{array}{l}\text { water and superficial } \\
\text { active agents (SAAs) }\end{array}$ & $\begin{array}{l}01 \mathrm{wt} \%, 0.025 \mathrm{wt} \% \\
\text { and } 0.05 \mathrm{wt} \% \text { (of } \\
\text { cement) }\end{array}$ & $\begin{array}{l}\text { 1) Stirring of the SAAs and water } \\
\text { Ultrasonic disruption in } 1-6 \\
\text { stages (duration of each stage: } 5 \\
\text { min.) }\end{array}$ & $\begin{array}{l}\text { UV-Vis Spectroscopy } \\
\text { Sedimentation test }\end{array}$ \\
\hline [21] & GNP & $\begin{array}{l}\text { water and melamine } \\
\text { dispersant }\end{array}$ & $\begin{array}{l}0.2 \mathrm{~g} \text { GNPs with } 1 \mathrm{~g} \\
\text { dispersant } / 200 \mathrm{~g} \\
\text { water } / 4 \mathrm{~g} \text { cement. }\end{array}$ & $\begin{array}{l}\text { Hand stirring of water and } \\
\text { dispersant. } \\
\text { High power ultrasonic vibration } \\
\text { for } 5 \text { min and cooling down in a } \\
\text { water bath for another } 5 \text { min. (3 } \\
\text { times) }\end{array}$ & $\begin{array}{l}\text { Visual rating } \\
\text { Image analysis }\end{array}$ \\
\hline$[22]$ & $\begin{array}{c}\text { Multilayer } \\
\text { Graphene } \\
\text { Sheets (MLG) }\end{array}$ & isopropanol & $\begin{array}{l}0 \% \text { to } 0.033 \% \text { by } \\
\text { weight of cement }\end{array}$ & $\begin{array}{c}\text { MLG and Isopropanol solutions was } \\
\text { directly poured in the matrix. No } \\
\text { additives (superplasticizer, water- } \\
\text { reducing agents, or surfactants) were } \\
\text { employed. }\end{array}$ & $\begin{array}{l}\text { Visual rating } \\
\text { Scanning Electron } \\
\text { Microscopy (SEM) }\end{array}$ \\
\hline [23] & GO & $\begin{array}{l}\text { water and } \\
\text { superplasticizer (solid } \\
\text { power) }\end{array}$ & $\begin{array}{c}0.01 \mathrm{wt} \%, 0.03 \mathrm{wt} \% \\
\text { and } 0.05 \mathrm{wt} \% \text { of } \\
\text { cement }\end{array}$ & $\begin{array}{l}\text { 1) GO and water were stirred } \\
\text { uniformly. } \\
\text { The superplasticizer was added } \\
\text { and the solution was stirred until } \\
\text { complete dissolution } \\
\text { 3) The solution was ultrasonicated for } \\
5 \text { min. }\end{array}$ & $\begin{array}{c}\text { Visual rating } \\
\text { Atomic force } \\
\text { microscopy (AFM) }\end{array}$ \\
\hline$[10]$ & $\begin{array}{l}\text { Chemically } \\
\text { Functionalized } \\
\text { Multiwall CNTs }\end{array}$ & $\begin{array}{l}\text { water with and without } \\
\text { surfactant }\end{array}$ & $0.1 \mathrm{wt} \%$ & $\begin{array}{l}\text { Sonication with probe type sonicator for } \\
15 \text { min ( } 3 \text { s pulse, } 1 \mathrm{~s} \text { wait cycles) at } \\
\text { constant temperature } 23^{\circ} \text { using an ice- } \\
\text { cooled bath. }\end{array}$ & $\begin{array}{c}\text { Transition Electron } \\
\text { Microscopy (TEM) } \\
\text { DLS } \\
\text { Thermal conductivity } \\
\text { measurements }\end{array}$ \\
\hline [14] & $\begin{array}{l}\text { Polycarboxylate } \\
\text { chemically } \\
\text { modified GNPs }\end{array}$ & $\begin{array}{l}\text { propylene glycol and } \\
\text { water }\end{array}$ & $\begin{array}{c}0.25,0.50,0.75 \text { and } \\
1.0 \mathrm{wt} \%\end{array}$ & $\begin{array}{l}\text { Ultrasonication for } 200 \mathrm{~min} \text { in an } \\
\text { ultrasound bath }\end{array}$ & $\begin{array}{l}\text { DLS } \\
\text { Rheology and viscosity } \\
\text { measurements }\end{array}$ \\
\hline [11] & GO & $\begin{array}{l}\text { solution of chloride salts } \\
\text { of } \mathrm{Ca}^{2+}, \mathrm{K}^{+} \text {and } \mathrm{Na}^{+}\end{array}$ & $0.035 \mathrm{mg} / \mathrm{mL}$ & $\begin{array}{l}\text { Sonication for } 15 \text { min with a cup-horn } \\
\text { sonicate processor }\end{array}$ & $\begin{array}{l}\text { Visual Rating } \\
\text { DLS }\end{array}$ \\
\hline [15] & $\begin{array}{l}\text { GO and reduced } \\
\text { GO }(\mathrm{rGO})\end{array}$ & $\begin{array}{l}\text { water and } 17 \text { organic } \\
\text { solvents }\end{array}$ & $0.5 \mathrm{mg} / \mathrm{mL}$ & $\begin{array}{l}\text { Sonication in an ultrasound bath cleaner } \\
\text { for } 1 \mathrm{~h} \text { and then mildly centrifugation at } \\
500 \mathrm{rpm} \text { for } 90 \mathrm{~min}\end{array}$ & $\begin{array}{l}\text { UV-Vis Spectroscopy } \\
\text { Raman Spectroscopy }\end{array}$ \\
\hline
\end{tabular}




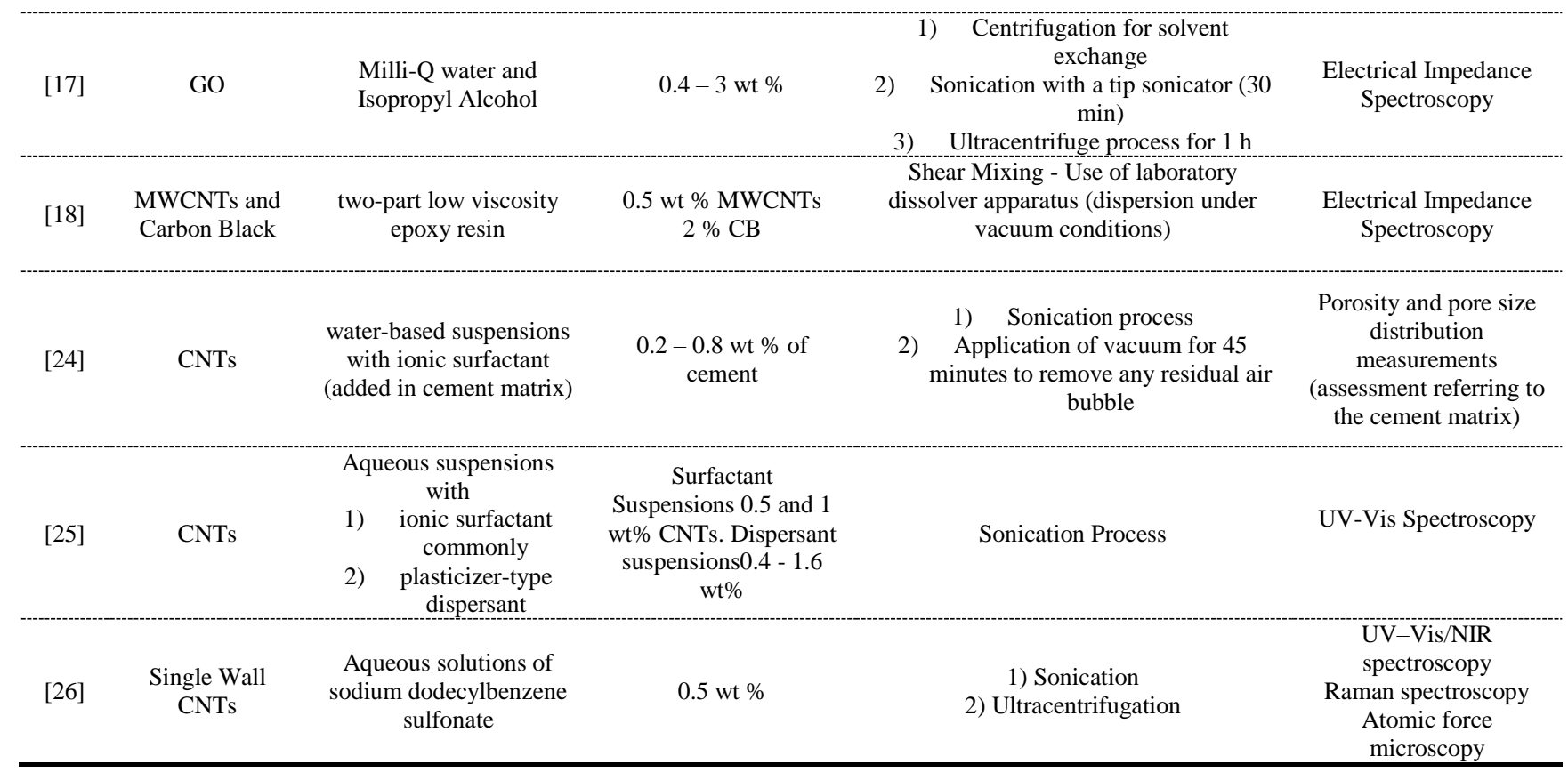

\subsection{Materials}

Graphene Oxide (GO) was synthesized at the University of Ioannina, Department of Materials Science (powder) was added to a mixture of $400 \mathrm{~mL}$ sulfuric acid $\left(\mathrm{H}_{2} \mathrm{SO}_{4} 95-97 \%\right)$ and $200 \mathrm{~mL}$ nitric acid $\left(\mathrm{HNO}_{3}\right.$ $65 \%$ ) in an ice bath, the mixture was stirred for 45 minutes. Then 100 g powdered $\mathrm{KClO}_{3}$ was slowly added in the mixture in small portions. After $18 \mathrm{~h}$ the reaction was terminated by pouring the mixture into deionized water. The product was washed thoroughly until $\mathrm{pH}$ of 6.0 was attained. The sample dried at room temperature.

The structural characteristics of Graphite and GO were studied with FT-IR and the results can be seen in Figure 2Figure 2a. Graphite does not absorb infrared light and that explains the absence of clear peaks. On the other hand, GO presents several peaks which come from the vibrations of Oxygen groups, while the carbon double-bond vibrations $(C=C)$ appear at $1630 \mathrm{~cm}^{-1}$. More specifically, the peak at $3440 \mathrm{~cm}^{-1}$ corresponds to the extension vibrations of $\mathrm{C}-\mathrm{OH}$ and the humidity. The peaks at $1720 \mathrm{~cm}^{-1}$ and 1059 $\mathrm{cm}^{-1}$ come from the carboxyl group vibrations of the bonds $\mathrm{C}=\mathrm{O}$ and $\mathrm{C}-\mathrm{O}_{2}$ respectively. The deformation vibrations of hydroxyls of $\mathrm{C}-\mathrm{OH}$ groups are spotted at $1391 \mathrm{~cm}^{-1}$ and finally the peaks at $806 \mathrm{~cm}^{-1}$ and $1200 \mathrm{~cm}^{-1}$ correspond to the bond vibrations $\mathrm{C}-\mathrm{O}$ and $\mathrm{C}-\mathrm{O}-\mathrm{C}$ of the epoxy-groups. The results are in accordance with other GO spectra, such as reported in [27] and [28].

The Raman spectrum of GO was measured at the University of Ioannina and is given in the diagram of 
239

240

241

242

243

244

245

246

247

248

249

250

251

252

253

254

255

256

257

259

to $\mathrm{sp}^{3}$ hybridization due to imperfections and deformations during Graphite oxidation. $1^{\text {st }}$ order $\mathrm{G}$ Band at $1597 \mathrm{~cm}^{-1}$ is attributed to $\mathrm{sp}^{2}$ hybridized carbon atoms of the Graphite net. The ratio (ID/IG) of the D and $\mathrm{G}$ bands shows the formation of functional oxygen groups during the oxidation process and was found equal to 0.84 .

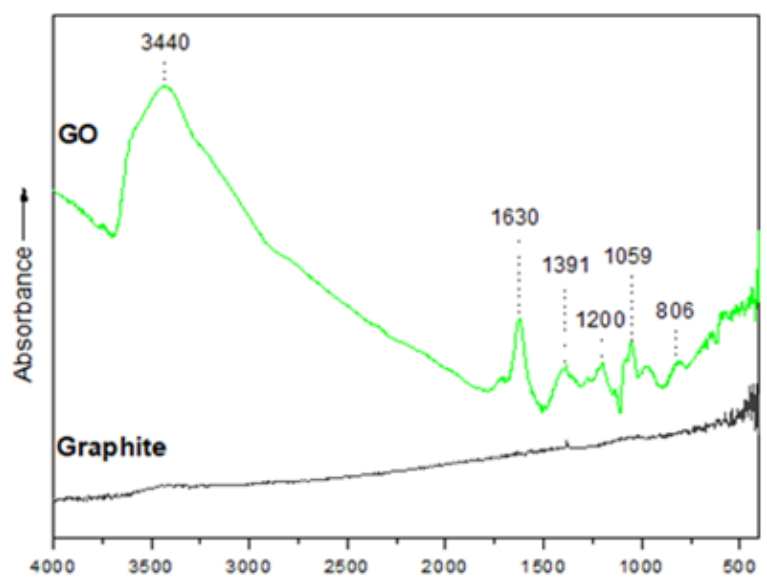

(a) Wavenumbers $\left(\mathrm{cm}^{-1}\right)$

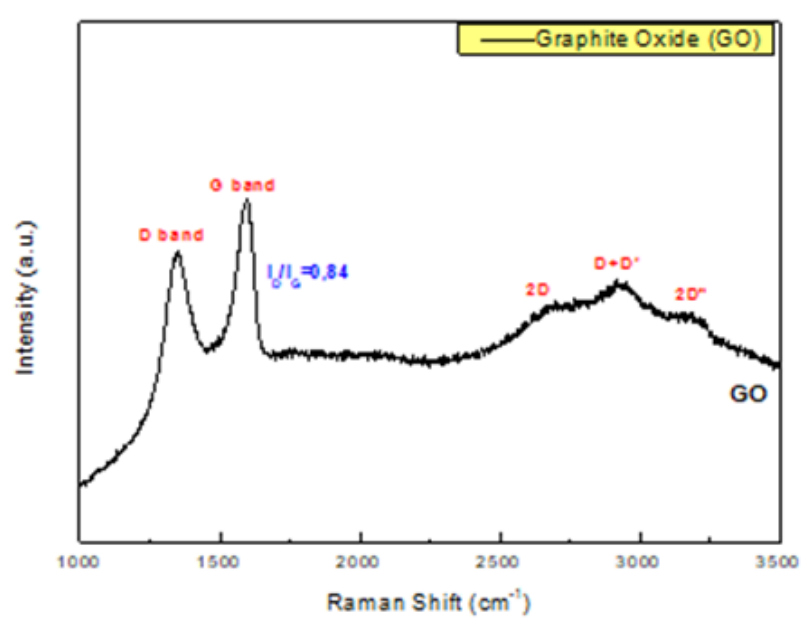

(b)

Figure 2: (a) FT-IR spectrum of Graphite and GO (b) Raman spectrum of GO.

The dispersion medium in this study was bottled water, more representative of water used in cement applications than Milli-Q water. The water samples were produced by Epirotic Bottling Industry S.A. (VIKOS S.A.), Ioannina, Greece. The $\mathrm{pH}$ value of the water sample was 7.3. Shih et al. [29] showed that at low pH values, the carboxyl groups of GO are protonated such that the GO sheets form aggregated due to the lower degree of hydrophilicity. At higher $\mathrm{pH}$, the carboxyl groups are deprotonated. On the other hand, Wu et al. [30] found that at alkaline $\mathrm{pH}$ with cation presence $\mathrm{GO}$ suspensions destabilize due to cross-linking of GO sheets through interacting with GO surfaces. Taking these facts into account, a product with slightly alkaline $\mathrm{pH}$ with low concentration of ions was chosen.

\subsection{Experimental methods}

Five different GO solutions were prepared and the exact amounts of GO and bottled water are presented in Table 2Table 2 . The GO quantities were selected so as the suspensions could be afterwards used for the preparation of cement-based nanocomposites at concentrations ranging from $0.05 \mathrm{wt} \%$ and up to 0.20 wt\% of the binder, as shown in the last column of Table 2Table 2. GO and water were weighed and placed in a beaker for the dispersion process and were hand-stirred before the first measurement.

Table 2. Mix proportions of the investigated GO dispersions.

\begin{tabular}{cccc}
\hline Solution number $(\#)$ & GO $(\mathrm{g})$ & Water $(\mathrm{mL})$ & wt \% of binder \\
\hline GO_0.05 & 0.07 & 100 & $0.05 \%$ \\
GO_0.10 & 0.14 & 100 & $0.10 \%$
\end{tabular}




$\begin{array}{cccc}\text { GO_0.15 } & 0.21 & 100 & 0.15 \% \\ \text { GO_0.175 } & 0.25 & 100 & 0.175 \% \\ \text { GO_0.20 } & 0.28 & 100 & 0.20 \%\end{array}$

261 The dispersion process was accomplished by applying ultrasonication energy with a probe type 262 ultrasonicator. The energy generator was the VCX-500 model and the nozzle model was CV-334 model, 263 both produced by the company SONICS \& MATERIALS ${ }^{\circledR}$. A temperature sensor was also used to simultaneously record the temperature values. The process consists of 360 ultrasonication cycles with each cycle containing a $15 \mathrm{~s}$ pulse and a $30 \mathrm{~s}$ wait. Therefore, the total amount of time needed for each solution is $4.5 \mathrm{~h}$, a time frame that corresponds to about $100 \mathrm{~kJ}$ of ultrasonication energy. The ultrasonication experimental setup is shown in Figure 3. The impedance scans were recorded for different accumulated ultrasonication energy values, namely $3 \mathrm{~kJ}, 12 \mathrm{~kJ}, 30 \mathrm{~kJ}, 65 \mathrm{~kJ}$ and $100 \mathrm{~kJ}$ for $100 \mathrm{~mL}$ each of the different investigated GO dispersions.

The effect of ultrasonication energy on the functional groups of GO was also observed for a given concentration (namely $0.15 \mathrm{wt} \%$ ) through the recording of the FT-IR Spectra with a Brucker - Tensor 27 spectrometer and Raman Spectra. Spectra at different ultrasonication energies were recorded at the same accumulated ultrasonication energy levels, namely at $3 \mathrm{~kJ}, 12 \mathrm{~kJ}, 30 \mathrm{~kJ}, 65 \mathrm{~kJ}$, and $100 \mathrm{~kJ}$. The dispersion evaluation included optical microscopy with a Leica DM-RX microscope at samples ultrasonicated at the respective ultrasonication energy values. The micrographs obtained from the optical microscopy were subjected to image analysis using the ImageJ software [31] to determine the average 277 agglomerates size-of agglomerates.

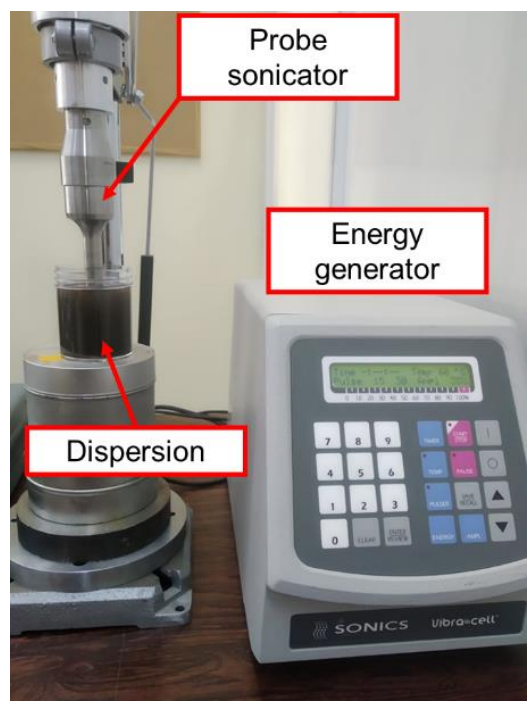

Figure 3. The experimental test set-up with the ultrasonication equipment on the GO dispersion of the present study. 
EIS was performed during the ultrasonication process using a Dielectric Thermal Analysis System DETA-SCOPE ${ }^{\circledR}$ supplied by ADVISE, Chios, Greece as shown in Figure 4Figure 4. The hardware setup was connected to an interdigital dielectric sensor IDEX ${ }^{\circledR}$, film-shaped, produced by Netzsch ${ }^{\circledR}$, Germany. The specific sensor was selected for the present application due to the small geometrical dimensions, approximately $10 \mathrm{~mm}$ in width and $30 \mathrm{~mm}$ in length. EIS with an IDEX sensor is a high accuracy- and established analysis method already used to investigate various well-known systems, as in [32], [33] and[34].

Additionally, the selected impedance measuring device is light weight, making the whole experimental setup portable and very easy to use in almost all possible applications. The DETA-SCOPE ${ }^{\circledR}$ applies sinusoidal excitation voltage of $10 \mathrm{~V}$ amplitude with frequency ranging from $0.1 \mathrm{~Hz}$ to $100 \mathrm{kHz}$. The measurements are recorded by the data acquisition software of the system. The first tests were performed on (plain) bottled water, followed by the five GO dispersions with different GO concentrations. For each dispersion, more than 20 impedance scans were recorded during the whole ultrasonication process and the process was repeated twice for each different concentration of the dispersion. Each dispersion was produced three times $\underline{(3 \mathrm{x})}$ to record the respective spectrum so as to ensure repeatability of the procedure.

Processing and interpretation of the impedance measurements can be accomplished by studying the Equivalent Circuit Model (ECM) [35]. This procedure is usually challenging, because more than one possible solution may fit the experimental data accurately, e.g. [36]. The issue of the non-singularity of the fitted model can be overcome if there is a deep understanding of the physiochemical processes and phases included in the system under investigation (e.g. double layer capacitance, solution resistance, polarization resistance, or porous electrodes).

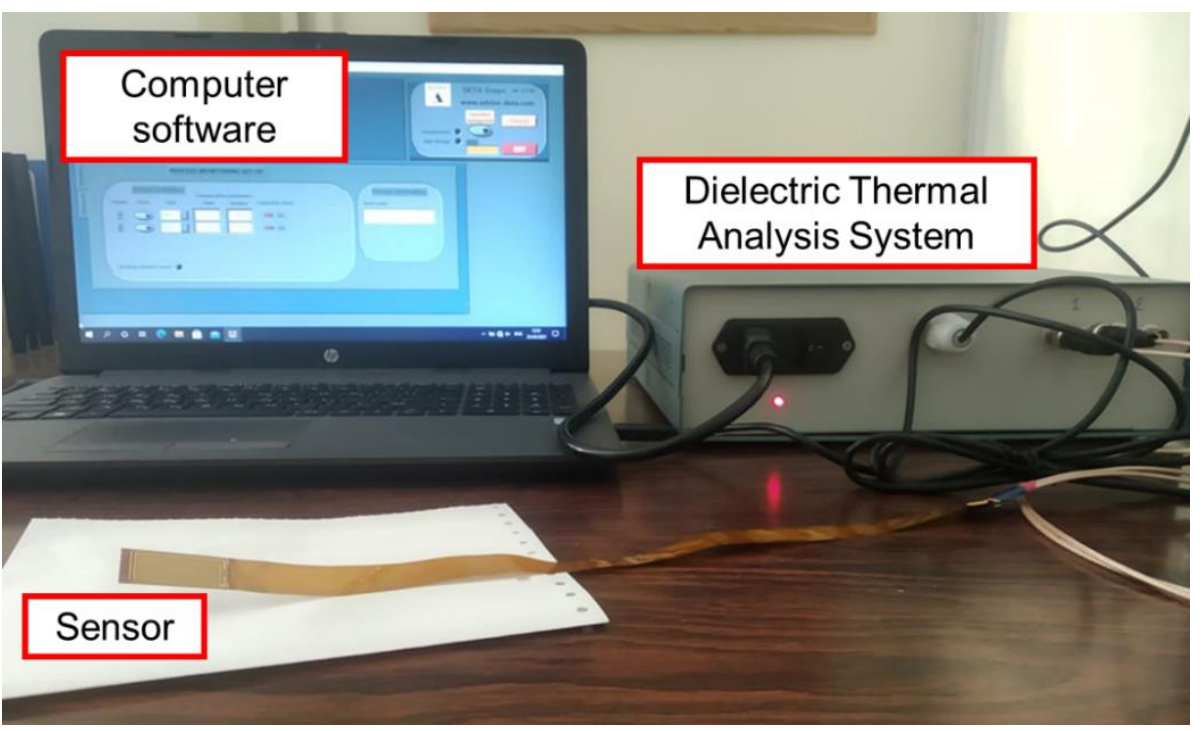


326

327

328

329

330

331

332

333

334

335

336

337

338

339

340

341

342

343

344

345

346

347

\section{Experimental results}

\subsection{Instrumental analysis methods}

The FT-IR spectra were recorded for all the above-mentioned ultrasonication energy values and the results are presented in Figure 5, where the peaks at $1600 \mathrm{~cm}^{-1}$ and $1100 \mathrm{~cm}^{-1}$ are marked. The goal is to investigate whether the high accumulated ultrasonication energy values can destroy the already formed, specific functional groups. It is already known by Zhang et al. [37] that ultrasonic conditions lead to the exfoliation of graphene oxide [37]. For this reason, the ratio of two standard GO peaks was calculated for the different energies. It is known that the peak at 1600 is related to the sp2 lattice of the Graphene structure, while the 1100 peak refers to C-O- functional group. The ratio of the intensity of the peaks is calculated for all energies (Intensity $1600 /$ Intensity ${ }_{100}$ ). The calculated ratio increases as the ultrasonication energy value increases, showing that the GO structure is affected by high accumulated ultrasonication energy. All the main peaks continue to exist, but their intensity gradually changes, indicating an affected chemical structure. This implies that a mechanism is evident dealing with the destruction of the functional groups at the surface of the nanostructures, or perhaps The present results eould be explained by ato the partial reduction of the GO sheets (exfoliation of graphene oxide) by ultrasonicationsenication. It is also noted that the peak at $2200-2500$ is attributed to the presence of GO.

The Raman spectra also confirms a change in the GO structure with high accumulated ultrasonication energy values. The characteristic bands are also marked in Figure 5, namely D-band and G-band. The ratio of the intensity of D/G Bands was also calculated and it is acan be considered as a measure of defects in the structure [38]. Likewise, Farah et al. [39] used the same ratio to study the reduction phenomena. As shown in the graph, the ratio of the intensity of those peaks towers decreases as ultrasonication energy increases, thus showing consistency with the FT-IR results.
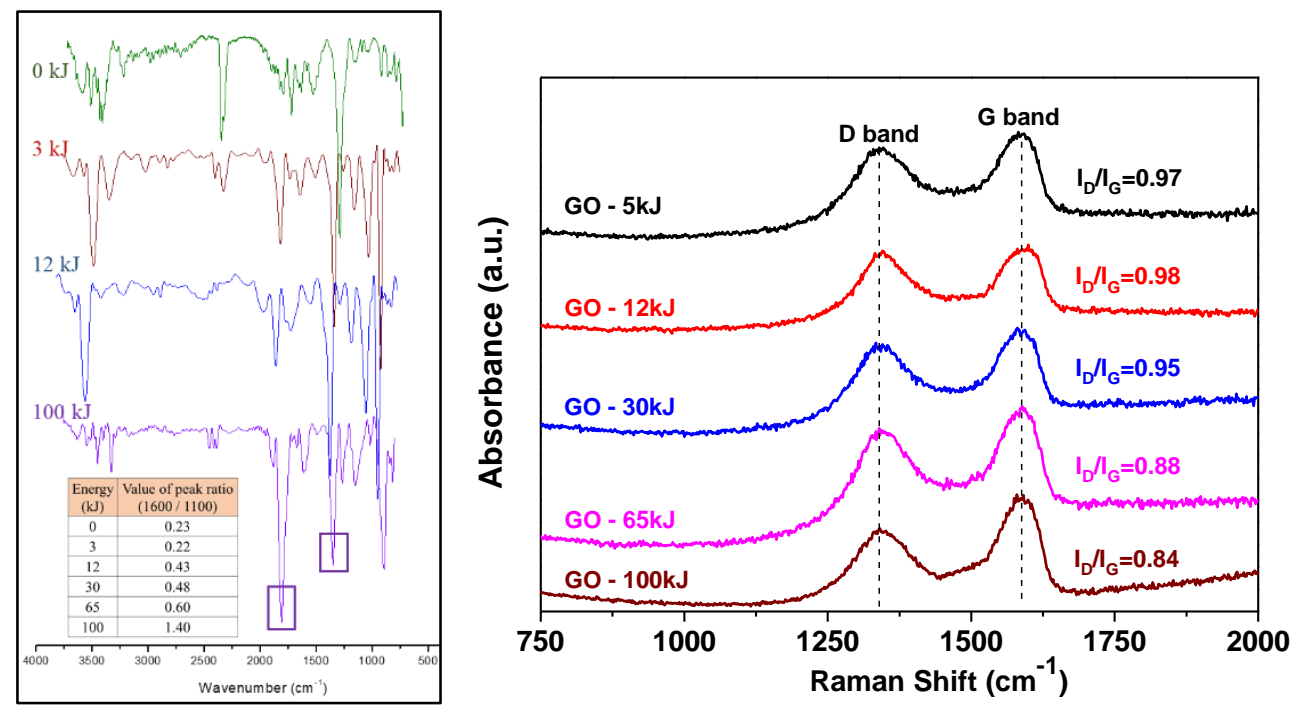
389

Figure 5: FT-IR spectrum (left) and Raman spectrum (right) of GO_0.15 (0.15 wt \%) dispersion at different ultrasonication energy values.

Figure 6Figure 6 displays the images obtained from the optical microscopy analysis and for the different accumulated ultrasonication energy values. As can be seen from the Figure, large agglomerates can be noticed at the non-ultrasonicated samples, since they were not ultrasonicated at all with. Thethe average size of the noticeable agglomerates is being approximately $45 \mu \mathrm{m}$. The application of low $\mathrm{A}$ small amount of -ultrasonication energy level $(3 \mathrm{~kJ})$ is enough to break up the largest agglomerates - and the nanostructures start to disperse. More specifically, there are two distinct groups of agglomerates can be identified. The first of themgroup contains the larger agglomerates of the order of magnitude of $30 \mu \mathrm{m}$ in diameter ( $30 \%$ smaller than the ones with $0 \mathrm{~kJ}$ energy) and the second ene group contains the lower agglomerates of the order of magnitude of $13 \mu \mathrm{m}$ in diameter $(\sim 60 \%$ smaller than the ones with $0 \mathrm{~kJ}$ energy). After the application of $12 \mathrm{~kJ}$ ultrasonication energy, the nanostructures are even better dispersed and quite few agglomerates were noticed, having with an average diameter of approximate 21 $\mu \mathrm{m}$.

Further application of ultrasonic_ationenergy leads to a better dispersion of the nanoparticles, since the number of the agglomerates is further reduced. For instance, at $30 \mathrm{~kJ}$ ultrasonication energy value, the average agglomerate diameter is less than $10 \mu \mathrm{m}$. However, at $100 \mathrm{~kJ}$ ultrasonication energy value, several agglomerates have started to form again, and the average diameter of the largest ones is approximately $15-20 \mu \mathrm{m}$, though this time they are uniformly dispersed.

The reason for this re-agglomeration with the high ultrasonication energy level that can be attributed to the alteration of chemical structure of the nanostructures, i.e. the destruction of hydrophilic groups and of the decrease of the lateral size of the GO (often called as exfoliation in the literature). Hydrophobic agglomeration is a phenomenon used to describe the aggregation of hydrophobic particles in aqueous suspension due to the hydrophobic attraction between the particles [40]. Thus, hydrophobic agglomeration takes place, because extensive amounts of ultrasonic energy lead to destruction of hydrophilic groups and a more graphene-like structure (hydrophobic structure). 


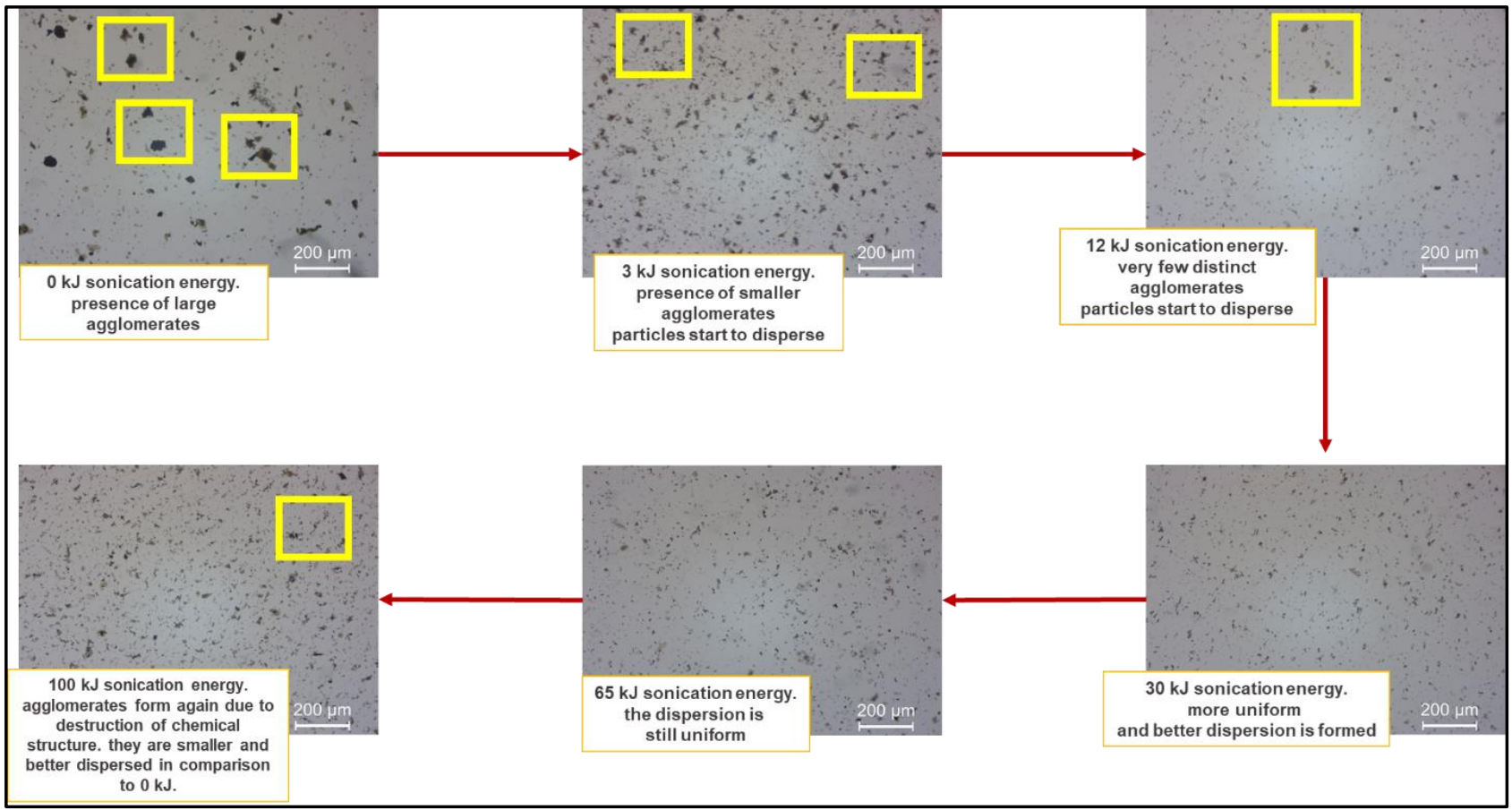

Figure 6: Optical microscopy images for the GO $0.15 \mathrm{wt} \%$ dispersion and for the different ultrasonication energy

421 For comparison purposes, Figure 7Figure 7 shows the side view of the beaker with the GO dispersion $422(100 \mathrm{ml})$ at $0.15 \mathrm{wt} \%$ concentration and for the different investigated ultrasonication energy values. After $42312 \mathrm{~kJ}$, the colour of the dispersion seems to be more uniform all over the container. This observation with 424 a naked eye may result to erroneous interpretation, since the optical microscopy results showed completely different results in terms of agglomeration size. To this end, it is recommended that the visual rating is not an appropriate method to evaluate the "quality" of the dispersions or the dispersion control of the nanostructures.
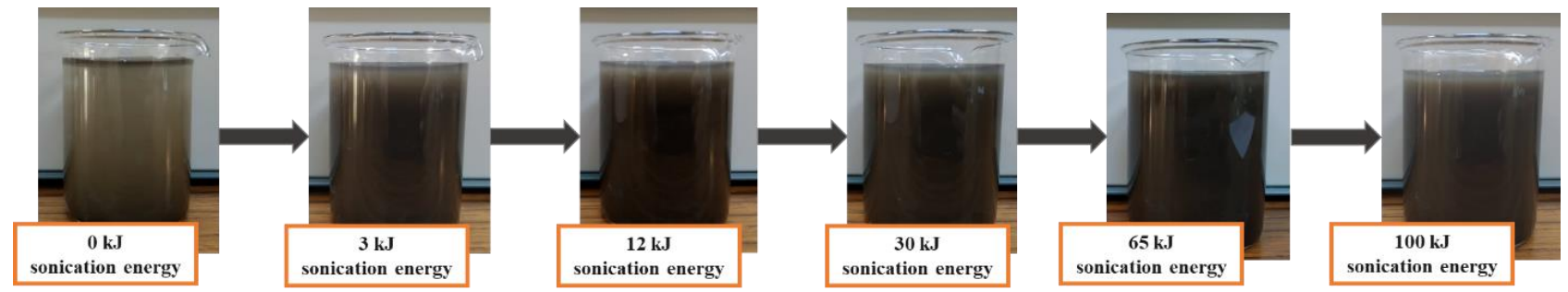

Figure 7: Visual evolution of the side view of the GO $0.15 \mathrm{wt} \%$ dispersion for the different investigated

\subsection{Electrical impedance spectroscopy results}

432 The first set of measurements was conducted on bottled water to capture the background impedance of 433 water used in the study and to ensure the repeatability of the procedure. The tests were repeated three 434 times $(3 \mathrm{x})$ and repeatability of the dielectric measurements was assured. The Bode impedance plots of 
453 bottled water in Figure 8Figure 8 present the impedance modulus $|\mathrm{Z}|$ and phase angle $\operatorname{argZ}$ measurements 454 of the bottled water $\forall$.versus test frequency. As expected, the Bode impedance plot shows that the bottled water is not affected by the ultrasonication energy level and the impedance vector is characteristic of 456 water.
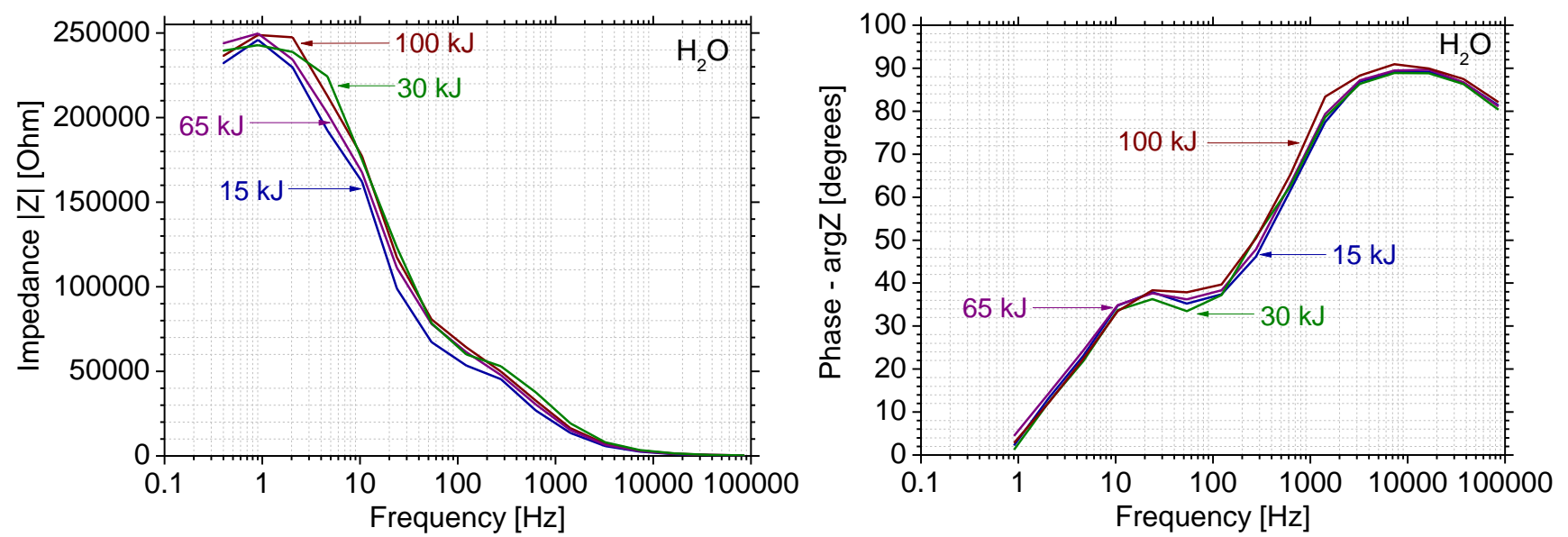

457

458 459

460

461

462

463

464

465

466

467

468

469

470

Figure 8: Measurements of impedance modulus (left) and phase angle (right) versus test frequency for the bottled water (solvent).

The Bode impedance plots in Figures 9a to 9e refer to the five (5) investigated GO concentrations and present the impedance vector against test frequency for different accumulated ultrasonication energy values. The GO_0.05 dispersion exhibits the highest impedance modulus values. There is a general tendency for increasing impedance modulus at low frequencies when the ultrasonication energy increases with the exception of the highest GO concentration. The dominance of ionic conductivity is evident in the GO dispersions at frequencies below $100 \mathrm{~Hz}$ considering the interdigital structure of the sensors and the fringing electric field created above the sensor surface. The above-mentioned tendency could be a result of partial reduction of GO with ultrasonication as there will be less ions after reduction. As the concentration of GO in the aqueous dispersions increases, the overall magnitude of the impedance vector decreases indicating higher concentration of charged species, such as ions, in the electric field. Qualitative and quantitative analysis of the spectra will be made-discussed in the following section. 
471
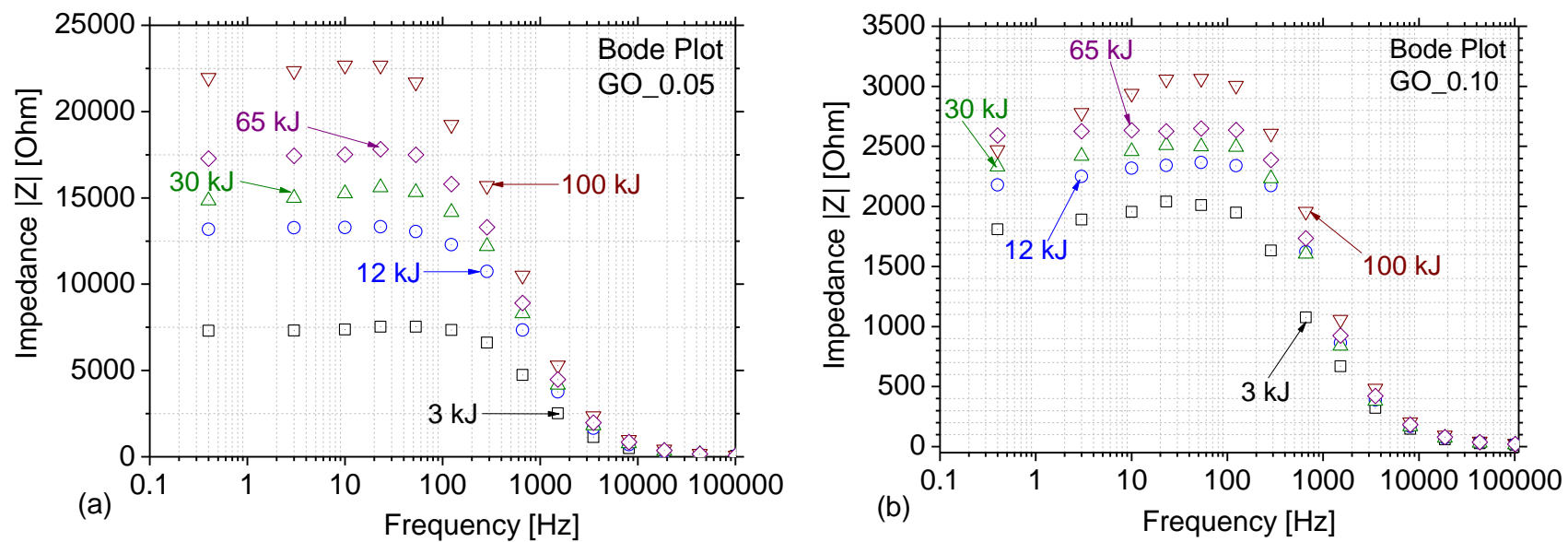

472
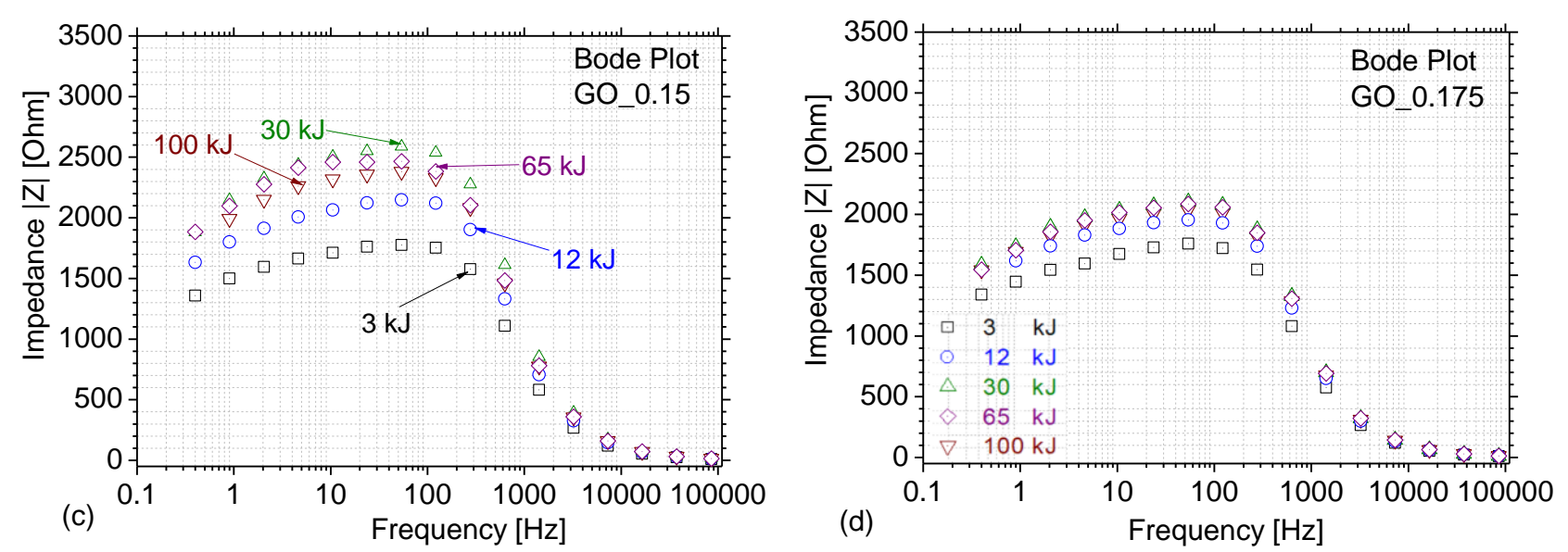

473

474

475

476

477

478

479

480

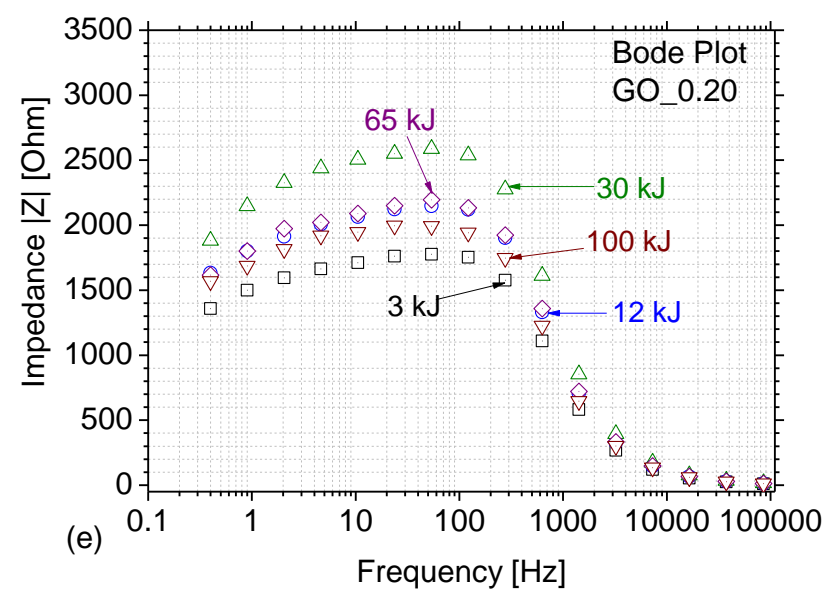

Figure 9: Bode plots of the five different investigated GO dispersions (GO concentration from 0.05 wt $\%$ and up to $0.20 \mathrm{wt} \%$ ) at different ultrasonication energy levels.

As the ultrasonication energy increases, it is expected that the dispersion becomes more uniform with

477 lower size of agglomerates as well as that GO reduction is promoted. Both of these effects lead to increasing impedance levels in the GO dispersion. By the application of ultrasonication energy; the form of cavitation micro-bubbles and their collapse because of the energy excess leads to the creation of microjets and shockwaves, thus facilitating de-bundling to achieve better dispersion of nanoparticles [41]. 


\section{Discussion of the results}

482

483 48 485 486 487 488 489 490 491 492

493
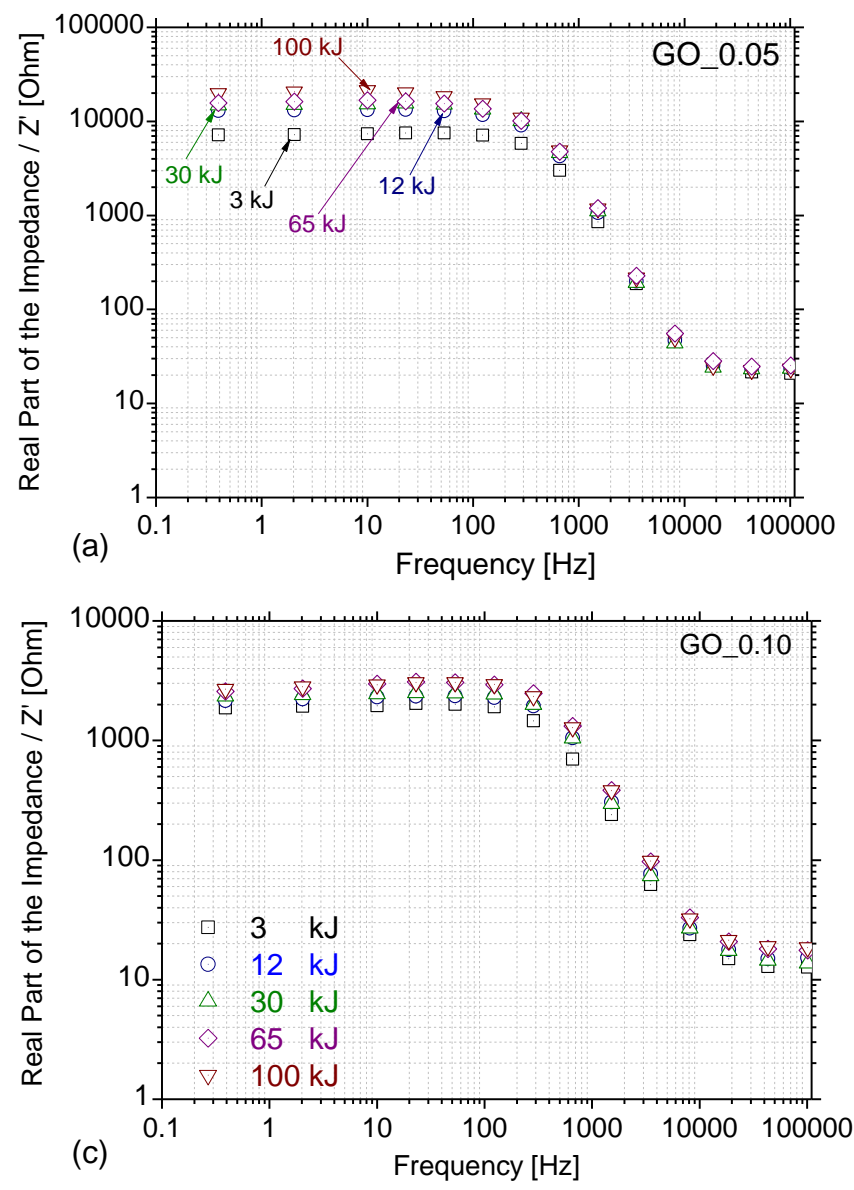
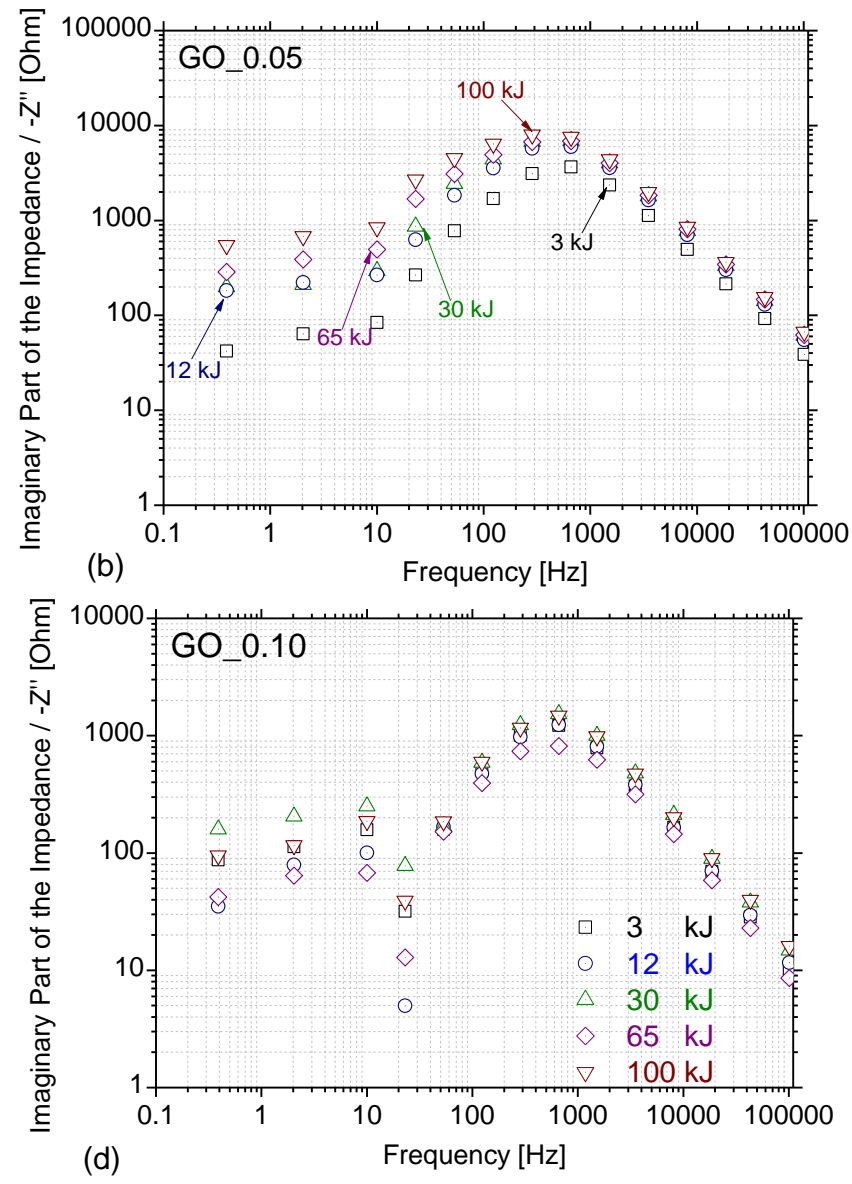

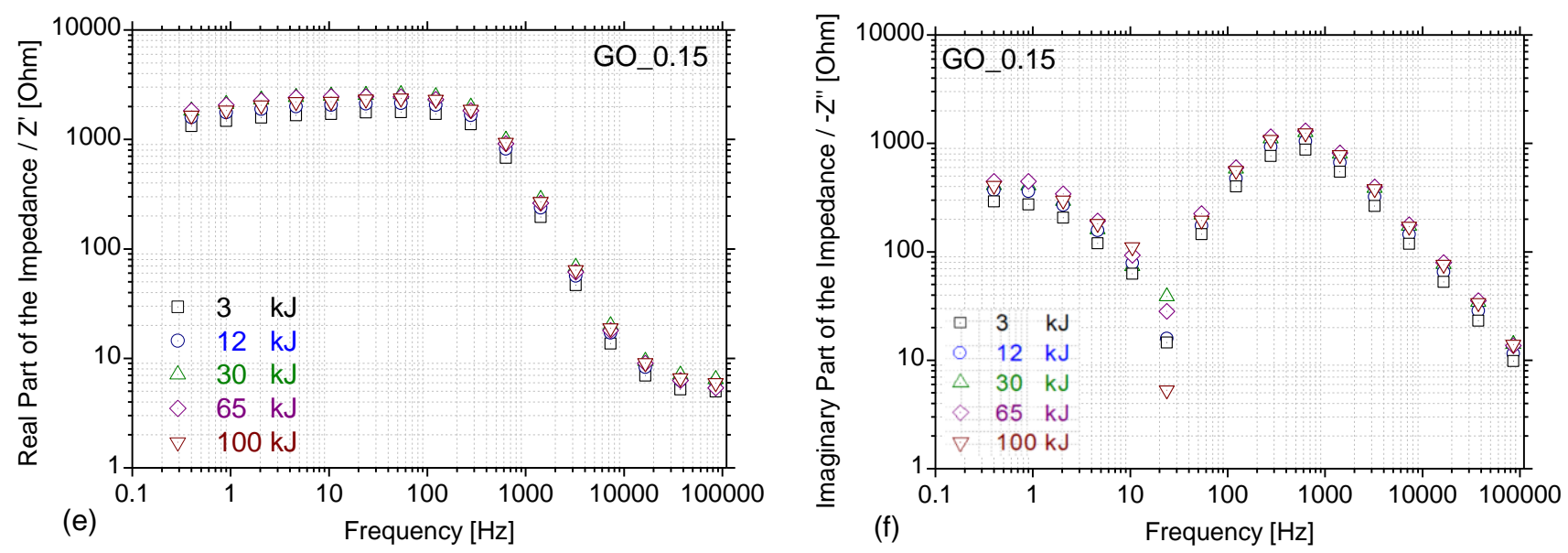

495
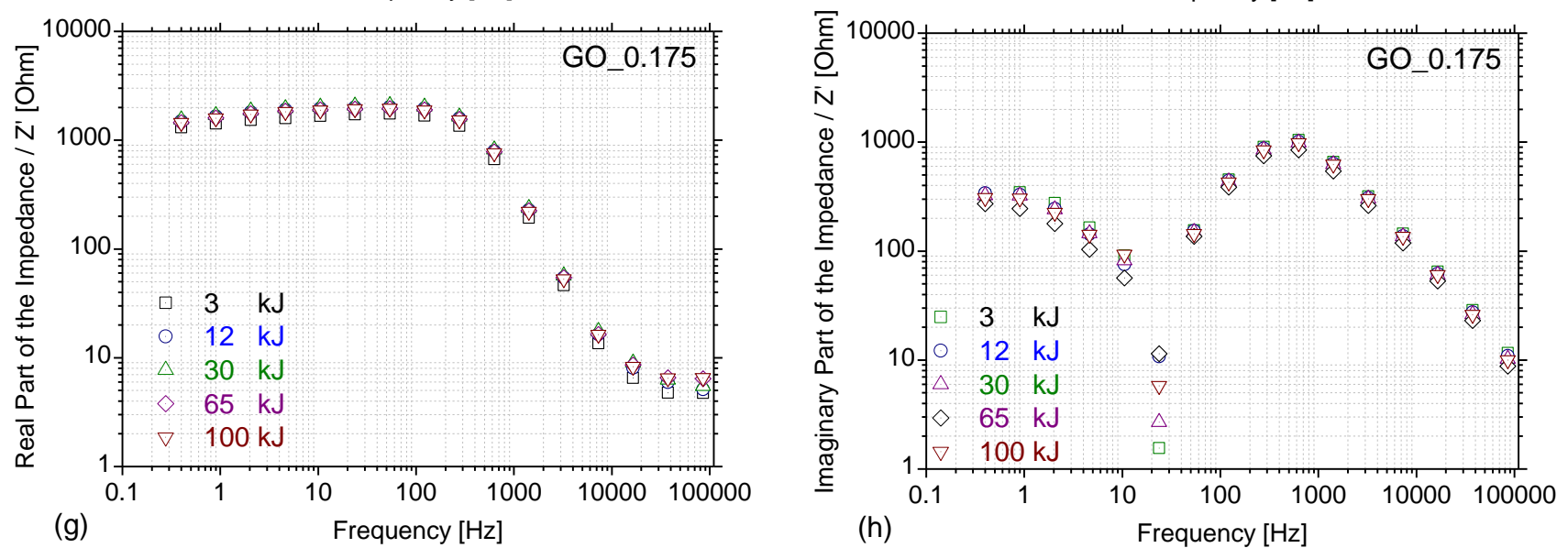

496

497

498

499

500

501

502

503

504

505

506
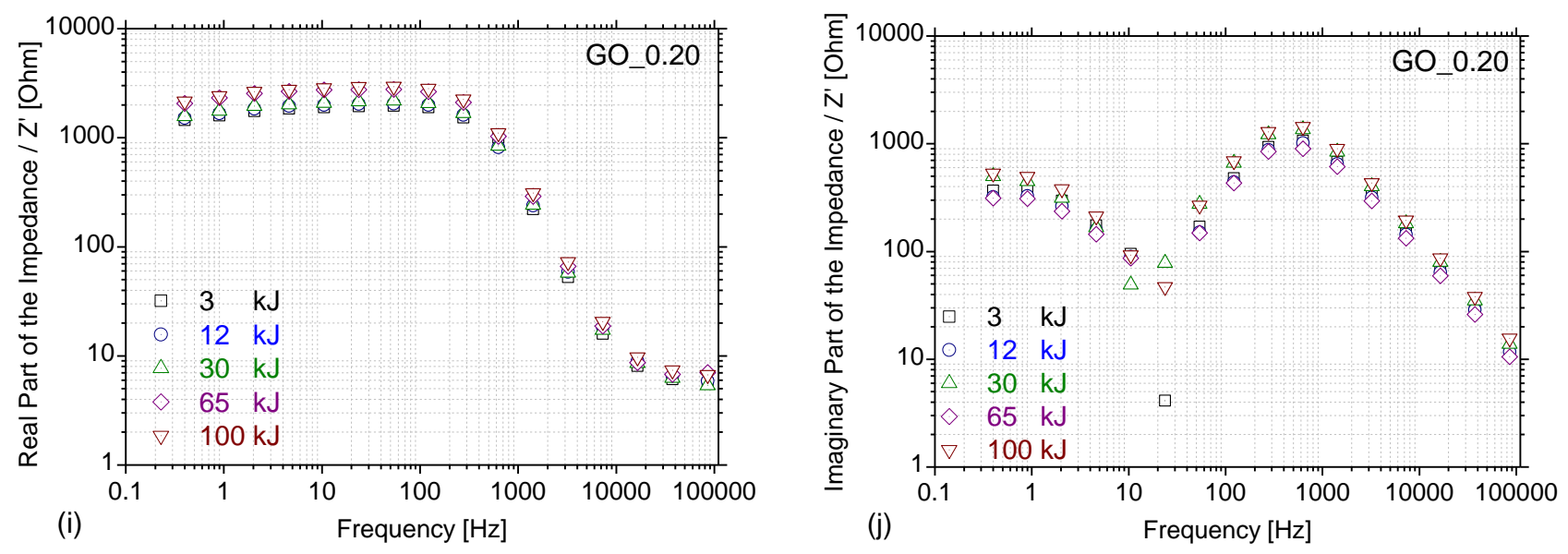

Figure 10. Real and imaginary parts of the impedance for the investigated GO dispersions (GO concentration from $0.05 \mathrm{wt} \%$ and up to $0.20 \mathrm{wt} \%$ ) and for the different ultrasonication energy levels.

\subsection{Equivalent circuit modelling}

The proposed equivalent circuit modelling (ECM) is an evolution of the classical Randle-cell model [42] that contains elements corresponding to the different processes present in our system, i.e. the interface 05 between the dispersion ${ }_{2}-$ and - the Kapton film of the sensor and the active phase of nanoparticles dispersion. As shown in Figure 11, the ECM consists of two branches according to the previous 
507 description with four elements. The capacitor $C_{1}$ and the resistor $R_{1}$ are the double layer capacitance and 508 the charge transfer resistor, respectively and they refer to the electrical double layer at the interface of 509 the dispersion and the film. In series with this branch we find the components of the water / GO 510 nanostructures phase in terms of a parallel connection of the constant phase element $(C P E)$, which is 511 symbolized with $Q$, and the resistor $R_{2}$.

512

513

514

515

516

517

518

519

520

521

522

523

524

525

526

527

528

529

530

531

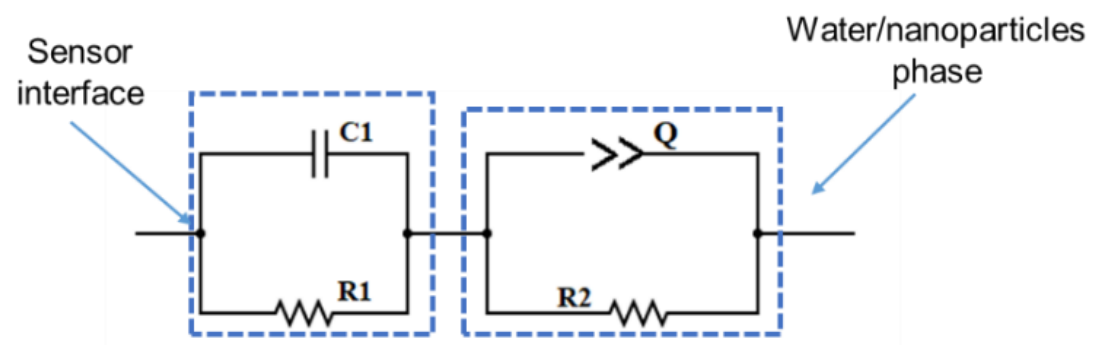

Figure 11: Proposed equivalent circuit model for the aqueous GO dispersions.

Table 34: Characteristics of the elements used for the proposed equivalent circuit model.

\begin{tabular}{ccc}
\hline Element & Impedance $(\mathrm{Z})$ & Units \\
\hline$R_{1}, R_{2}$ & $R$ & Ohm \\
$Q($ or $C P E)$ & $1 /\left[Q_{0}(\mathrm{j} \omega)^{\mathrm{n}}\right]$ & $\mathrm{F} \cdot \mathrm{s}^{\mathrm{n}-1}$ \\
$C$ & $1 /(\mathrm{j} \omega \mathrm{C})$ & $\mathrm{F}$ \\
\hline
\end{tabular}

$C P E$ is a non-intuitive circuit element that is used to describe responses of real-world systems [43] and will be used in the present investigation to address in our system the reasons for its appearances are inhomogeneity and non-uniform current distribution. $Q_{0}$ corresponds to the admittance of the ideal capacitance and $n$ is a constant with a range of 0 to 1 , with $n=1$ referring to a pure capacitor and $n=0$ referring to a pure resistor, e.g. [43]. Likewise, Han et al. [44] introduced the constant phase elements to describe stacked graphene oxide in solid humidity sensors. As reported in that study this research article and also noted in the present researchinvestigation, the frequency behaviour of GO is too complicated to be presented using simple RC circuits. Hence, the introduction of $C P E$ was deemed necessary as a circuit component $_{2}$ commonly used to express an imperfect capacitor in a circuit of distributed resistors and capacitors. The reason for this non-uniform current distribution lies firstly on the van der Waals attractions among nanoparticles and the double-layer electrostatic repulsions, e.g. [30] and [45]. Also, the presence of metal and non-metal ions can cause a destabilisation of the GO mixtures, playing a critical role in the dispersion [46].

Figure 12 shows the equivalent circuit model (ECM) predictions versus the experimental results for a given ultrasonication energy, namely $65 \mathrm{~kJ}$ and for three different GO dispersions. It can be seen that the 

are given in Table 5, again for the $65 \mathrm{~kJ}$ ultrasonication energy and for all investigated concentrations.

555

556 557

558 559

560

561

562

563

564
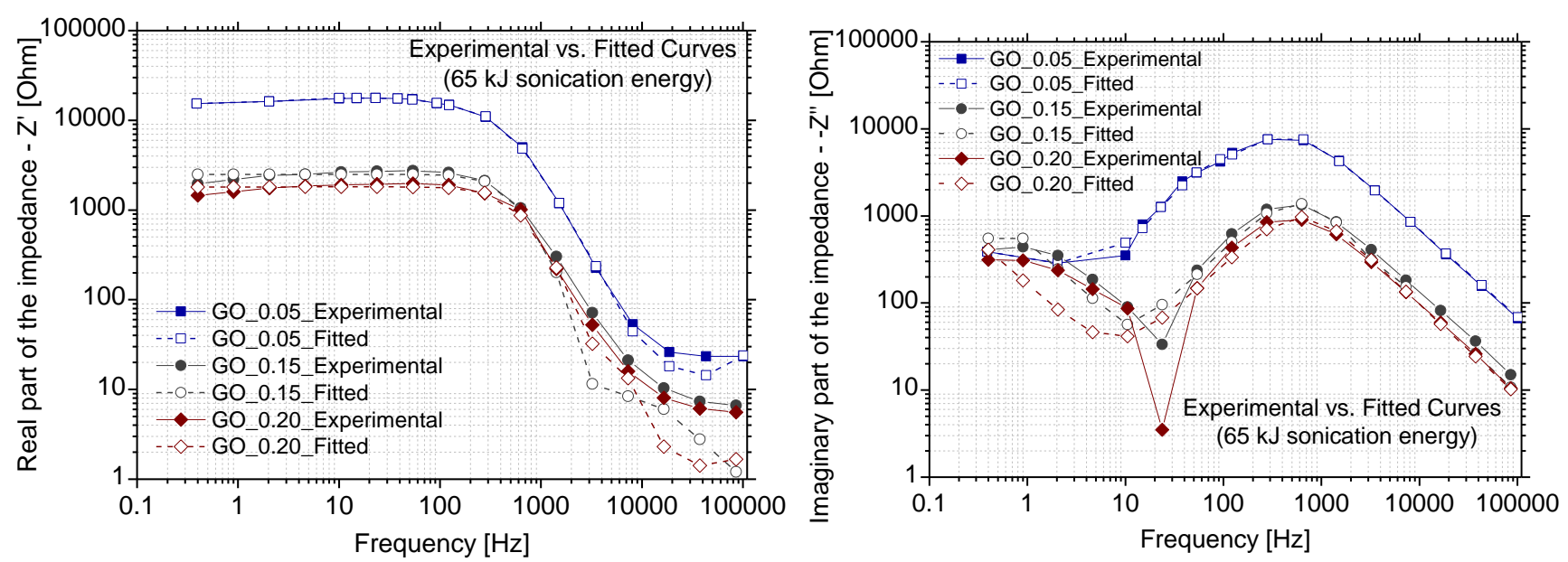

Figure 12: Calculated results for the proposed equivalent circuit model at $65 \mathrm{~kJ}$ ultrasonication energy and for three different GO concentrations.

Table 45: Values of the circuit elements of the model shown in Figure 11 for all different GO concentrations at $65 \mathrm{~kJ}$ ultrasonication energy value and the respective relative standard deviation.

\begin{tabular}{c|c|c|c|c|c}
\hline Element & GO_0.05 & GO_0.10 & GO_0.15 & GO_0.175 & GO_0.20 \\
\hline $\boldsymbol{R}_{\mathbf{1}}(\mathbf{O h m})$ & $1.6 \cdot 10^{4}( \pm 1.3 \%)$ & $2.1 \cdot 10^{3}( \pm 7.9 \%)$ & $1.8 \cdot 10^{3}( \pm 3.7 \%)$ & $1.8 \cdot 10^{3}( \pm 6.8 \%)$ & $2.2 \cdot 10^{3}( \pm 7.7 \%)$ \\
$\boldsymbol{C}_{\mathbf{1}}(\mathbf{F})$ & $2.2 \cdot 10^{-8}( \pm 1.2 \%)$ & $4.4 \cdot 10^{-4}( \pm 1.5 \%)$ & $7.5 \cdot 10^{-4}( \pm 27.4 \%)$ & $6.4 \cdot 10^{-4}( \pm 21.8 \%)$ & $9.8 \cdot 10^{-4}( \pm 28.5 \%)$ \\
$\boldsymbol{R}_{\mathbf{2}}(\mathbf{O h m})$ & $1.6 \cdot 10^{3}( \pm 14.3 \%)$ & $2.5 \cdot 10^{3}( \pm 1.0 \%)$ & $2.4 \cdot 10^{3}( \pm 2.2 \%)$ & $1.9 \cdot 10^{3}( \pm 2.3 \%)$ & $1.8 \cdot 10^{3}( \pm 2.5 \%)$ \\
$\boldsymbol{Q}\left(\mathbf{F} \cdot \mathbf{s}^{\mathbf{n}-\mathbf{1}}\right)$ & $2.2 \cdot 10^{-7}( \pm 27.2 \%)$ & $2.2 \cdot 10^{-7}( \pm 13.7 \%)$ & $7.1 \cdot 10^{-8}( \pm 32.1 \%)$ & $7.8 \cdot 10^{-8}( \pm 35.5 \%)$ & $9.9 \cdot 10^{-8}( \pm 39.4 \%)$ \\
$\boldsymbol{n}(-)$ & $0.98( \pm 5.2 \%)$ & $0.98( \pm 1.6 \%)$ & $0.96( \pm 4.1 \%)$ & $0.96( \pm 5.1 \%)$ & $0.94( \pm 4.5 \%)$ \\
\hline
\end{tabular}

Although there is an overall good fit of the experimental data, the proposed circuit fails to model the relaxation phenomenon with high accuracy and more specifically the local minimum in the imaginary impedance spectra. For that reason, a revised ECM has been proposed to model the response of the dispersions for GO concentrations higher than $0.10 \mathrm{wt} . \%$, which is presented in Figure 13Figure 13. In an attempt to improve the representation of the electrode polarisation phenomena at the sensor surface at lower frequencies and its separation to the relaxation phenomena at the bulk of the dispersion, the $C-R_{1}$ branch of the first ECM is replaced by a capacitor in series with a $Q-R$ element. The addition of an extra $Q-R$ element in series to the first proposed circuit will be more suitable for the high concentrations of the GO dispersions, but it will be not so appropriate for the dilute solutions. Figure 14 demonstrates the fitting results of GO_0.15 dispersion at different ultrasonication energy values, while the respective values of each element can be seen in Table 6. The comparison of the fit of ECMs to the experimental data shows that the values of the parameters in both $Q-R$ elements change slightly within the range of the standard deviation of their values. Because the $n$ values of the $C P E$ s is close to 1 , the $Q$ value is 
574 representative a pure capacitor, and the fact that the $Q$ value remains nearly unchanged makes sense 575 physically as the permittivity of the solution is expected to remain unchanged considering the low 576 concentration of GO in the dispersion. Furthermore, the observed slight drop in $R_{2}$ is expected as the GO 577 concentration increases. Therefore, to accurately model the dispersion, the sensor interphase is better 578 described by the revised ECM.

579

580

581

582

583

584 585

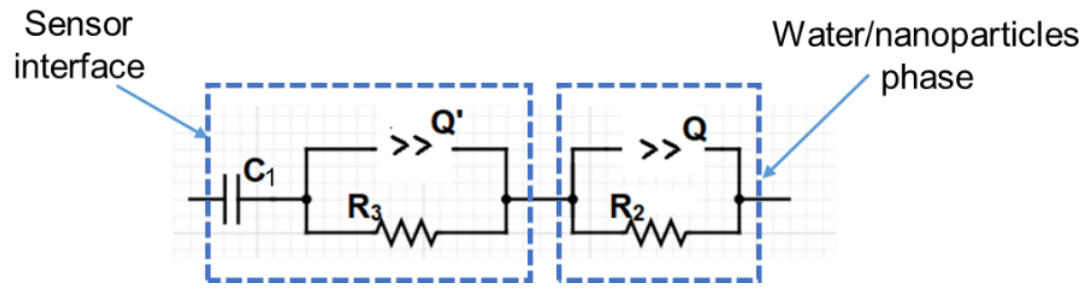

Figure 13: Updated ECM for the investigated GO dispersions with GO concentrations higher than 0.10 wt.\%.
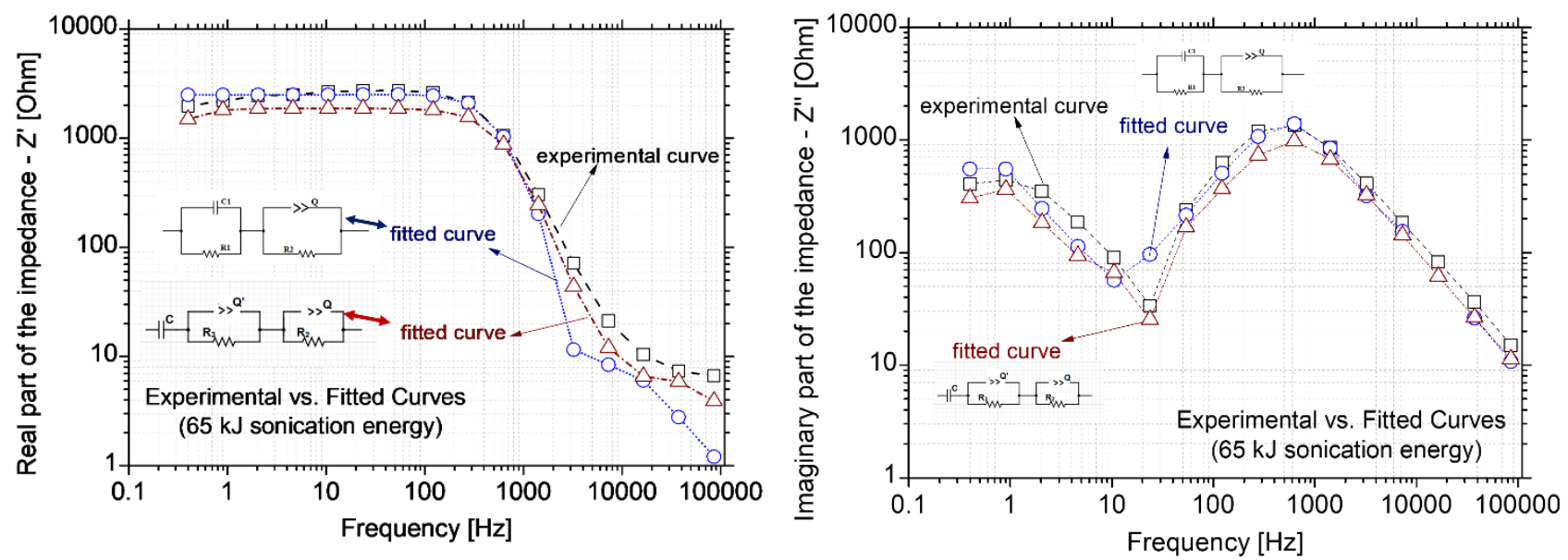

Figure 14: Comparison of the predictions the two proposed circuit models at higher GO concentrations for the (a) real and (b) imaginary parts of the impendance.

Table 56: Values and the respective relative std. deviation of the proposed circuit elements at the updated ECM at 65 kJ ultrasonication energy value.

\begin{tabular}{c|c|c|c}
\hline Element & GO_0.15 & GO_0.175 & GO_0.20 \\
\hline $\boldsymbol{C}_{\mathbf{1}}(\mathbf{F})$ & $2.9 \cdot 10^{-4}( \pm 6.3 \%)$ & $3.4 \cdot 10^{-4}( \pm 34.1 \%)$ & $4.2 \cdot 10^{-4}( \pm 45.3 \%)$ \\
$\boldsymbol{R}_{\mathbf{3}}(\mathbf{O h m})$ & $2.4 \cdot 10^{3}( \pm 7.7 \%)$ & $2.1 \cdot 10^{3}( \pm 7.1 \%)$ & $1.8 \cdot 10^{3}( \pm 9.6 \%)$ \\
$\boldsymbol{Q}^{\prime}(\mathbf{F})$ & $1.2 \cdot 10^{-4}( \pm 3.4 \%)$ & $1.5 \cdot 10^{-4}( \pm 3.2 \%)$ & $1.7 \cdot 10^{-4}( \pm 4.1 \%)$ \\
$\boldsymbol{n}^{\prime}(-)$ & $1.03( \pm 46.3 \%)$ & $1.02( \pm 44.1 \%)$ & $1.03( \pm 57.0 \%)$ \\
$\boldsymbol{R}_{\mathbf{2}}(\mathbf{O h m})$ & $2.3 \cdot 10^{3}( \pm 1.4 \%)$ & $2.0 \cdot 10^{3}( \pm 1.4 \%)$ & $1.8 \cdot 10^{3}( \pm 1.6 \%)$ \\
$\boldsymbol{Q}\left(\mathbf{F} \cdot \mathbf{s}^{\mathbf{n}-1}\right)$ & $7.6 \cdot 10^{-8}( \pm 22.1 \%)$ & $9.5 \cdot 10^{-8}( \pm 21.4 \%)$ & $1.2 \cdot 10^{-7}( \pm 25.7 \%)$ \\
$\boldsymbol{n}(-)$ & $0.96( \pm 4.1 \%)$ & $0.98( \pm 2.4 \%)$ & $0.97( \pm 2.9 \%)$ \\
\hline
\end{tabular}

586

587 The values of $R_{2}$ and $Q$ are given in Figure 15 as a function of ultrasonication energy and for different 588 GO concentrations. As far as the dependence of the ultrasonication energy on the ECM parameter values 589 is concerned, the fit has revealed small changes on the $Q-R$ element of the water - nanoparticles phase. 
590 As the $n$ value remained close to $1, Q$ is representative of pure capacitor and its value did not change 591 with the ultrasonication energy for each GO concentration. During senication-Tthere are two effects with 592 opposing expected effects on the impedance during ultrasonication: the breaking of GO agglomerates 593 towards a finer distribution which decreases the distance between the nanoparticles in the dispersion, 594 thus decreasing impedance levels. The second effect is the and the damage in the hydrophilic nature of 595 the nanostructure with simultaneous reduction-decrease of the lateral size of GO, which increases the impedance level. These effects cannot be discerned in the impedance spectra and the resulting parameters 598 of the ECMs. To this end, a sort of a kind of "optimal" ultrasonication energy must be considered to introduce the appropriate energy to break the large GO agglomerates and not to completely destroy the surface structure of the GO nanoparticles.
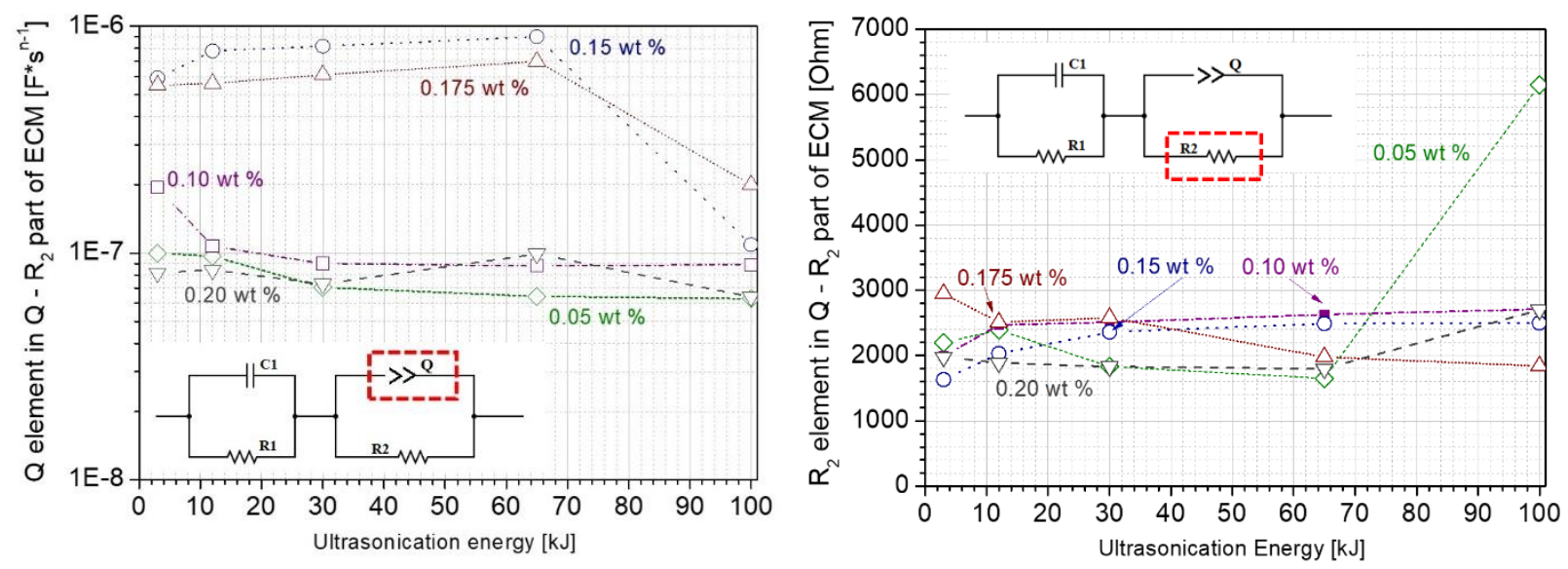

600

601

602

603

604

605

606

607

608

609

610

611

612

613

614

Figure 15: Values of elements $Q$ (left) and $R_{2}$ (right) of the proposed electrical circuit models.

\subsection{Introduction of a quality index in aqueous dispersions}

To facilitate the evaluation of the dispersion (dispersion control), a relevant quality index (QI) will be proposed. To this end, the proposed quality index can facilitate the dispersing stage of the nanostructures that, in latter stage, the appropriate dispersion can be mixed with the binder material and thus can be applied for the appropriate intervention.

Having examined the dispersion in terms of dielectric properties and having performed the appropriate instrumental analysis methods, the quality index that is proposed is the real part of the impedance [ $\left.Z^{\prime}\right]$ at a high frequency, higher than $10 \mathrm{kHz}$. The choice of the real part of the impedance was based on the fact that a decrease in $\mathrm{Z}^{\prime}$ is an indication of simple electrolyte in the solution, e.g. [17]. The suggestion of a high frequency value was selected in order to avoid polarisation and/or the relaxation phenomena that appear in lower frequencies in many physical and chemical systems, e.g. [47], [48]. In present study, Z' is taken at $20 \mathrm{kHz}$, as described in the following eqn. (1): 
616 As shown in Figure 16, $Z^{\prime}$ decreases as concentration increases, but for constant ultrasonication energy 617 level. As far as the ultrasonication energy is concerned, $Z^{\prime}$ presents a minimum at an intermediate 618 ultrasonication energy and for all investigated GO concentrations. This is logical, since the structure has 619 been affected due to partial destruction of functional groups, as shown by Raman and FT-IR analyses in 620 the previous sections. Taking Figure 16 into consideration, which contains all the previous analysis, for any concentration higher than GO_0.10 the $\mathrm{Z}^{\prime}$ value is distinctively small, thus resembling a good 623 electrolyte. Regarding ultrasonication energy, all GO concentrations display a local minimum at medium values of ultrasonication energy of $30 \mathrm{~kJ}$ or $65 \mathrm{~kJ}$. Therefore, an optimal combination of $0.15 \mathrm{wt} \%$ of the 624 binder ultrasonicated at about approximate $60 \mathrm{~kJ}$ is proposed, since it would require a smaller GO 625 concentration that would lead to less material used in real engineering applicationseonsumption.

626 However, any range from 0.15 wt $\%$ up to 0.20 wt \% of the binder ultrasonicated at an intermediate 627 energy level could be accepted.

628 To this end, the involvement of a quality index for the dispersion control of relevant nanostructures is 629 very tempting and would facilitate the quantitative selection by means of the appropriate concentration, 630 type and ultrasonication energy of the nanostructures. To the best of the authors' knowledge, such a quantitative index is not proposed in the literature so far for the dispersion control of any kind of 632 nanostructures.

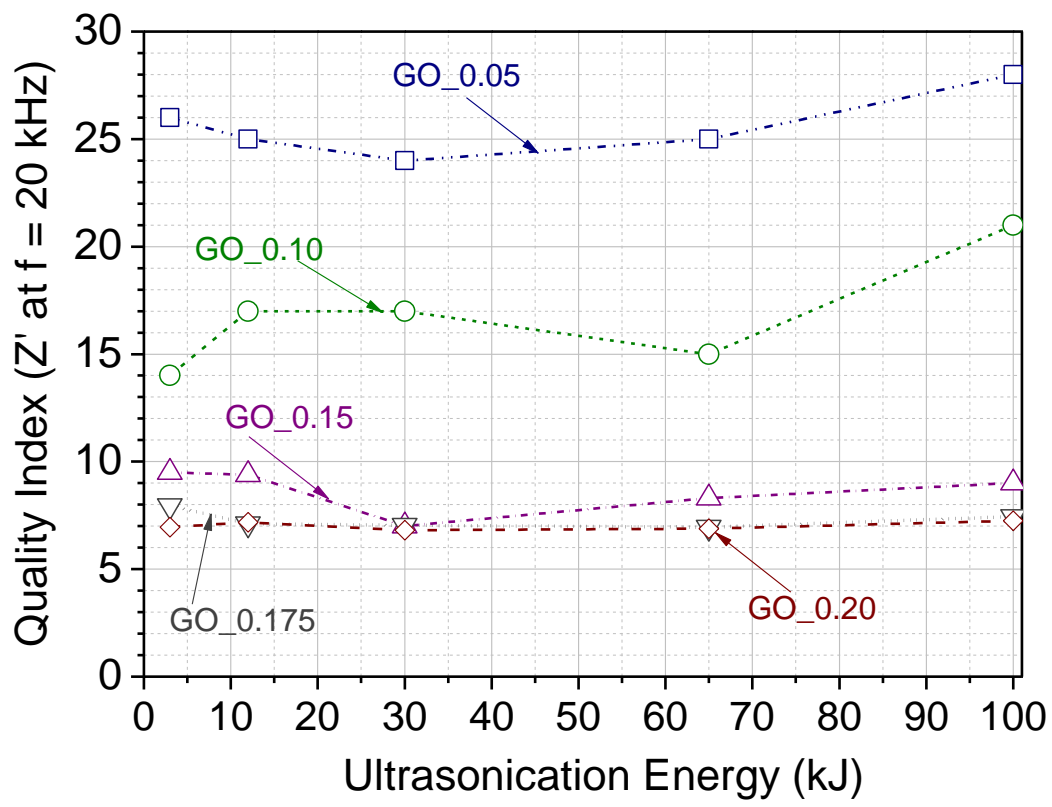
investigated GO dispersions. 
639 The conclusions of the present investigation can be summarised as follows:

640

641

642

643

644

645

646

647

648

649

650

651

652

653

654

655

656

657

658

659

660

661

662

663

664

665

666

667

- A novel method to study aqueous carbon nanostructure (Graphene Oxide - GO in the present investigation) dispersions is investigated, based on alternative current electrochemicalical impedance spectroscopy. The novelty also lies on the application of a very small sensor that can be used on field applications, where the application of instrumental analysis methods is not possible.

- The application of ultrasonication energy leads to two competing mechanisms. At the beginning the ultrasonic energy contributes to the formation of conductive networks as it effectively breaks the agglomerates. This was confirmed by dielectric measurements through the change in impedance values as well as by analytical investigations. Nevertheless, at high energy level the ultrasonication destroys the surface groups of the nanostructures and the GO-particles, decreases their lateral size and at high energy level tend to re-agglomerate.

- The GO-dispersions were modelled with the use of several equivalent circuit models. A constant phase element was found to better describe the inhomogeneities of the dispersion.

- A quality index was proposed for a quick, quantified evaluation of the dispersion degree. It is proposed this index to be equal to the real part of the impedance at a high frequency, as it is easy to be calculated and a low value in $\mathrm{Z}^{\prime}$ is an indication of simple electrolyte in the solution. Alse Additionally, there are no polarisation phenomena in such high frequencies.

- Based on the investigation on the specific application (i.e. nanostructures in aqueous solution for civil engineering applications), the optimal combination of concentration and ultrasonication energy is $0.15 \mathrm{wt} \%$ of the binder with ultrasonication energy values of approximate 30 to $65 \mathrm{~kJ}$.

\section{Acknowledgements}

The authors would like to acknowledge the financial support provided in the framework of the Research Project: AKEISTHAI - Self-Healing and Self-Sensing Nano-Composite Conservation Mortars (MIS 5031866), co-financed by Greece and the European Union. The GO nanomaterials were produced at the University of Ioannina, Department of Materials Science \& Engineering (Prof. D. Gournis and Prof. M. Karakassides) and under the framework of the joint research project "Self-healing and self-sensing nanocomposite conservation mortars - AKEISTHAI” among National Centre for Scientific Research “Demokritos", University of the Aegean, University of Ioannina, and cement manufacturer TITAN S.A..

\section{Conflict of Interest}

668 The authors declare that there are no known conflicts of interest associated with this publication. 
670 Conceptualization: N.D.A. and G.M.; methodology: A.E.D. and G.M.; experimental work: A.E.D.; 671 validation: N.D.A., G.M., P.P. and A.E.D.; writing-original draft preparation: A.E.D.; writing - review 672 and editing: N.D.A., G.M. and P.P.; All authors read and approved the manuscript.

673 References

674

[1] A. Alagarasi, "Chapter: 1," in Introduction to Nanomaterials, 2011, p. 76.

[2] C. Cha, S. Shin, N. Annabi, M. Dokmeci and A. Khademhosseini, "Carbon-Based Nanomaterials: MultiFunctional Materials for Biomedical Engineering,” ACS Nano, vol. 7, no. 4, p. 2891-2897, 2013.

[3] S. Park, K. Lee, G. Bozoklu, W. Cai, S. Nguyen and R. Ruoff, "Graphene Oxide Papers Modified by Divalent Ions-Enhancing Mechanical Properties via Chemical Cross-Linking,” ACS Nano, vol. 2, no. 3, pp. 572$578,2008$.

[4] A. Lawal, "Graphene-based nano composites and their applications. A review," Biosensors and Bioelectronics, vol. 141, pp. 11384-, 2019.

[5] Z. Metaxa, "Exfoliated graphene nanoplatelet cement-based nanocomposites as piezoresistive sensors: influence of nanoreinforcement lateral size on monitoring capability," Ciência \& Tecnologia dos Materiais, vol. 28, no. 1, pp. 73-79, 2016.

[6] R. Guo, Y. Suo, H. Xia, Y. Yang, Q. Man and F. Yan, "Study of Piezoresistive Behavior of Smart Cement Filled with Graphene Oxide," nanomaterials, vol. 11, p. 206, 2021.

[7] Y. Zare, K. Y. Rhee and D. Hui, "Influences of nanoparticles aggregation/agglomeration on the interfacial/interphase and tensile properties of nanocomposites," Composites Part B, vol. 122, pp. 41-46, 2017.

[8] L. Zhao, X. Guo, Y. Liu, C. Ge, Z. Chen and L. Guo, "Investigation of dispersion behavior of GO modified by different water," Carbon, vol. 128, pp. 255-269, 2018.

[9] M. Wang, H. Yao, R. Wang and S. Zheng, "Chemically functionalized graphene oxide as the additive for cement-matrix composite with enhanced fluidity and toughness," Construction and Building Materials, vol. 150, pp. 150-156, 2017.

[10] N. Sezer and M. Koç, "Stabilization of the aqueous dispersion of carbon nanotubes using different approaches," Thermal Science and Engineering Progress, vol. 8, pp. 411-417, 2018.

[11] A. Sabziparvar, E. Hosseini, V. Chiniforush and A. Korayem, "Barriers to achieving highly dispersed graphene oxide in cementitious composites: An experimental and computational study," Construction and Building Materials, vol. 199, pp. 269-278, 2019.

[12] J. Liu, J. Fu, Y. Yang and C. Gu, "Study on dispersion, mechanical and microstructure properties of cement paste incorporating graphene sheets," Construction and Building Materials, vol. 199, pp. 1-11, 2019. 
[13] D. Li, M. B. Muller, S. Gilje, R. B. Kaner and G. G. Wallace, "Processable aqueous dispersions of graphene nanosheets," Nature Nanotechnology, vol. 3, no. 2, pp. 101-105, 2008.

[14] J. P. Vallejo, G. Żyła, J. Fernández-Seara and L. Lugo, "Rheological behaviour of functionalized graphene nanoplatelet nanofluids based on water and propylene glycol:water mixtures," International Communications in Heat and Mass Transfer, vol. 99, pp. 43-53, 2018.

[15] D. Konios, M. M. Stlylianakis, E. Stratakis and E. Kymakis, "Dispersion behaviour of graphene oxide and reduced graphene oxide,” Journal of Colloid and Interface Science, vol. 430, pp. 108-112, 2014.

[16] D. D. Macdonald, "Reflections on the history of electrochemical impedance spectroscopy," Electrochimica Acta, vol. 51, pp. 1376-1388, 2006.

[17] M. Alfonso, J. Yuan, F. Tardani, W. Neri, A. Colin and P. Poulin, "Absence of giant dielectric permittivity in graphene oxide materials," Journal of Physics Materials, vol. 2, p. 045002, 2019.

[18] D. Baltzis, D. Bekas, G. Tzachristas, A. Parlamas, M. Karabela, N. Zafeiropoulos and A. Paipetis, "Multiscaled carbon reinforcements in ternary epoxy composite materials: Dispersion and electrical impedance study," Composites Science and Technology, vol. 153, pp. 7-17, 2017.

[19] F. He, R. Wang, C. Shi, R. Zhang, C. Chen, L. Lin and X. An, "Differential analysis of AC impedance spectroscopy of cement-based materials considering CPE behavior," Construction and Building Materials, vol. 143, pp. 179-188, 2017.

[20] H. Sun, Z. Ren, S. A. Memon, D. Zhao, X. Zhang and D. Li, "Investigating drying behavior of cement mortar through electrochemical impedance spectroscopy analysis," Construction and Building Materials, vol. 135, pp. 361-368, 2017.

[21] J. Tao, X. Wang, Z. Wang and Q. Zeng, "Graphene nanoplatelets as an effective additive to tune the microstructures and piezoresistive properties of cement-based composites," Construction and Building Materials, vol. 209, pp. 665-678, 2019.

[22] R. e Silva, P. de Castro Guetti, M. da Luz, F. Rouxinol and R. Gelamo, "Enhanced properties of cement mortars with multilayer graphene nanoparticles," Construction and Building Materials, vol. 149, pp. 378$385,2017$.

[23] H. Peng, Y. Ge, C. Cai, Y. Zhang and Z. Liu, "Mechanical properties and microstructure of graphene oxide cement-based composites," Construction and Building Materials, vol. 194, pp. 102-109, 2019.

[24] P. Alafogianni, K. Dassios, C. Tsakiroglou, T. Matikas and N. Barkoula, "Effect of CNT addition and dispersive agents on the transport properties and microstructure of cement mortars," Construction and Building Materials, vol. 197, pp. 251-261, 2019.

[25] P. Alafogianni , K. Dassios, S. Farmaki, S. Antiohos, T. Matikas and N.-M. Barkoula, "On the efficiency of UV-vis spectroscopy in assessing the dispersion quality in sonicated aqueous suspensions of carbon nanotubes," Colloids and Surfaces A: Physicochemical and Engineering Aspects, vol. 495, pp. 118-124, 2016.

[26] A. Blanch, C. E. Lenehan and J. S. Quinton, "Parametric analysis of sonication and centrifugation variables for dispersion of single walled carbon nanotubes in aqueous solutions of sodium dodecylbenzene sulfonate," Carbon, vol. 49, pp. 5213-5228, 2011. 
[27] C. Valencia, C. H. Valencia, F. Zulaga, M. E. Valencia and J. H. Mina, "Synthesis and Application of Scaffolds of Chitosan-Graphene Oxide by the Freeze-Drying Method for Tissue Regeneration," Molecules, vol. 23, pp. 2651-2667, 2018.

[28] N. Hu, Z. Yang, Y. Wang, L. Zhang, Y. Wang, X. Huang, H. Wei, L. Wei and Y. Zhang, "Ultrafast and sensitive room temperature NH3 gas sensors based on chemically reduced graphene oxide," Nanotechnology, vol. 25, no. 2, pp. 25502-25510, 2013.

[29] C.-J. Shih, S. Lin, R. Sharma, M. S. Strano and D. Blankschtein, "Understanding the pH-dependent behavior of graphene oxide aqueous solutions: A comparative experimental and molecular dynamics simulation study," Langmuir, vol. 28, no. 1, pp. 235-241, 2012.

[30] L. Wu, L. Liu, B. Gao, R. Muñoz-Carpena, M. Zhang, H. Chen, Z. Zhou and H. Wang, "Aggregation kinetics of graphene oxides in aqueous solutions: Experiments, mechanisms, and modeling," Langmuir, vol. 29, no. 49, pp. 15174-15181, 2013.

[31] C. A. Schneider, W. S. Rasband and K. W. Eliceiri, "NIH Image to ImageJ: 25 years of image analysis," Nature Methods, vol. 9, pp. 671-675, 2012.

[32] L. Lai, G. Carman, S. Chiou, P. Kukuchek and D. Echternach, "Processing monitoring of carbon/phenolic omposites using smart sensors," Smart Materials and Structures, vol. 4, pp. 118-125, 1995.

[33] M. Sernek and F. A. Kamke, "Application of dielectric analysis for monitoring the cure process of phenol formaldehyde adhesive," International Journal of Adhesion \& Adhesives , vol. 27, p. 562-567, 2007.

[34] U. Müller, C. Pretschuh, E. Zikulnig-Rusch, E. Dolezel-Horwath, M. Reiner and S. Knappe, "Dielectric analysis as cure monitoring system for melamine-formaldehyde laminates," Progress in Organic Coatings , vol. 90, p. 277-283, 2016.

[35] F. Ciucci, "Modeling electrochemical impedance spectroscopy," Current Opininion in Electrochemistry, vol. 13, pp. 132-139, 2019.

[36] E. Barsoukov and J. Macdonald, Impedance Spectroscopy: Theory, Experiment, and Applications, Hoboken,NJ: John Wiley \& Sons, Inc, 2005.

[37] C. Zhang, W. Lv, X. Xie, D. Tang, C. Liu and Q.-H. Yang, "Towards low temperature thermal exfoliation of graphite oxide for graphene production," Carbon, vol. 62, pp. 11-24, 2013.

[38] S. Claramunt, A. Varea, D. Lopez-Diaz, M. M. Velazquez, A. Cornet and A. Cicera, "The Importance of Interbands on the Interpretation of the Raman Spectrum of Graphene Oxide," The Journal of Physical Chemistry C, vol. 119, pp. 10123-10129, 2015.

[39] S. Farah, A. Farkas, J. Madarász and K. László, "Comparison of thermally and chemically reduced graphene oxides by thermal analysis and Raman spectroscopy," Journal of Thermal Analysis and Calorimetry, vol. 142, p. 331-337, 2020.

[40] P. Chen, H. Li, H. Yi, F. Jia, L. Yang and S. Song, "Removal of graphene oxide from water by floc-flotation," Separation and Purification Technology, vol. 202, p. 27-33, 2018.

[41] K. Muthoosamy and S. Manickam, "State of the art and recent advances in the ultrasound-assisted synthesis, exfoliation and functionalization of graphene derivatives," Ultrasonics - Sonochemistry, vol. 39, pp. 478493, 2017. 
[42] S. . M. Mahdi Alavi, A. Mahdi, S. J. Payne and D. A. Howey, "Identifiability of Generalized Randles Circuit Models," IEEE TRANSACTIONS ON CONTROL SYSTEMS TECHNOLOGY, vol. 25, no. 6, pp. 2112-2120, 2017.

[43] M. E. Orazem and B. Tribollet, Electrochemical Impedance Spectroscopy, Hoboke, NJ: Wiley, 2008.

[44] K. I. Han, S. D. Kim, W. S. Yang, H. S. Kim, M. Shin, J. P. Kim, I. G. Lee, B. J. Cho and W. S. Hwang, "Material characteristics and equivalent circuit models of stacked graphene oxide for capacitive humidity sensors," AIP Advances, vol. 6, p. 035203, 2016.

[45] M. W. Hahn and C. R. O'Melia, "Deposition and Reentrainment of Brownian Particles in Porous Media under Unfavorable Chemical Conditions: Some Concepts and Applications," Environmental Science \& Technology, vol. 38, no. 1, pp. 210-220, 2004.

[46] H. Wang and Y. H. Hu, "Electrolyte-induced precipitation of graphene oxide in its aqueous solution," Journal of Colloid and Interface Science, vol. 391, pp. 21-27, 2013.

[47] P. Mirtaheri, S. Grimnes and G. Martinsen, "Electrode polarization impedance in weak NaCl aqueous solutions," IEEE Transactions on Biomedical Engineering, vol. 52, no. 12, pp. 2093-2099, 2005.

[48] G. R. Olhoeft, "Low-frequency electrical properties," GEOPHYSICS, vol. 20, no. 12, pp. 2492-2503, 1985.

675

676 